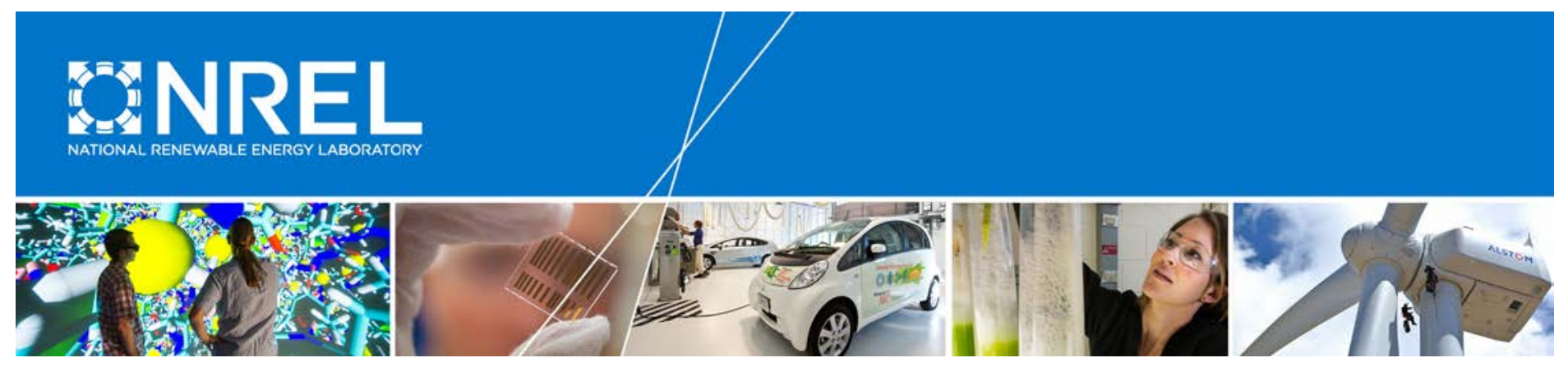

\title{
Reducing Wind Curtailment through Transmission Expansion in a Wind Vision Future
}

Jennie Jorgenson, Trieu Mai, and Greg Brinkman National Renewable Energy Laboratory

NREL is a national laboratory of the U.S. Department of Energy Office of Energy Efficiency \& Renewable Energy Operated by the Alliance for Sustainable Energy, LLC

This report is available at no cost from the National Renewable Energy Laboratory (NREL) at www.nrel.gov/publications.

Technical Report

NREL/TP-6A20-67240

January 2017

Contract No. DE-AC36-08G028308 
Reducing Wind Curtailment through Transmission Expansion in a Wind Vision Future

Jennie Jorgenson, Trieu Mai, and Greg Brinkman National Renewable Energy Laboratory

Prepared under Task No. WE14.CF03
National Renewable Energy Laboratory 15013 Denver West Parkway Golden, CO 80401

303-275-3000 • www.nrel.gov
NREL is a national laboratory of the U.S. Department of Energy Office of Energy Efficiency \& Renewable Energy Operated by the Alliance for Sustainable Energy, LLC

This report is available at no cost from the National Renewable Energy Laboratory (NREL) at www.nrel.gov/publications.

\section{Technical Report}

NREL/TP-6A20-67240

January 2017

Contract No. DE-AC36-08G028308 


\section{NOTICE}

This report was prepared as an account of work sponsored by an agency of the United States government. Neither the United States government nor any agency thereof, nor any of their employees, makes any warranty, express or implied, or assumes any legal liability or responsibility for the accuracy, completeness, or usefulness of any information, apparatus, product, or process disclosed, or represents that its use would not infringe privately owned rights. Reference herein to any specific commercial product, process, or service by trade name, trademark, manufacturer, or otherwise does not necessarily constitute or imply its endorsement, recommendation, or favoring by the United States government or any agency thereof. The views and opinions of authors expressed herein do not necessarily state or reflect those of the United States government or any agency thereof.

This report is available at no cost from the National Renewable Energy Laboratory (NREL) at www.nrel.gov/publications.

Available electronically at SciTech Connect http:/www.osti.gov/scitech

Available for a processing fee to U.S. Department of Energy and its contractors, in paper, from:

U.S. Department of Energy

Office of Scientific and Technical Information

P.O. Box 62

Oak Ridge, TN 37831-0062

OSTI http://www.osti.gov

Phone: 865.576.8401

Fax: 865.576.5728

Email: reports@osti.gov

Available for sale to the public, in paper, from:

U.S. Department of Commerce

National Technical Information Service

5301 Shawnee Road

Alexandria, VA 22312

NTIS http://www.ntis.gov

Phone: 800.553 .6847 or 703.605 .6000

Fax: 703.605.6900

Email: orders@ntis.gov 


\section{Acknowledgments}

This project was funded by the U.S. Department of Energy's (DOE's) Office of Energy Efficiency and Renewable Energy's Wind Energy Technologies Office. The following individuals provided valuable input during the analysis and publication process: Jose Zayas, Charlton Clark, and Patrick Gilman of DOE; Rich Tusing of Allegheny Science and Technology (senior advisor to the Wind Energy Technologies Office); Charlie Smith of the Utility Variable Generation Integration Group; Brian Parsons of the Western Grid Group; Michael Goggin of the American Wind Energy Association; Tom Carr of the Western Interstate Energy Board; and Eric Lantz, Ali Ehlen, Aaron Bloom, and Mike Meshek of the National Renewable Energy

Laboratory. Any errors or omissions are the sole responsibility of the authors. 


\section{Executive Summary}

The Department of Energy's 2015 Wind Vision study analyzed an aggressive scenario in which wind power served $35 \%$ of U.S. electricity consumption in 2050 and showed the potential for wind energy to provide substantial health, environmental, and economic benefits. Using a higher fidelity modeling framework we build on this research by assessing the operational feasibility of a similar high wind future in the western United States. For this analysis, we use a commercial unit commitment and economic dispatch model to simulate grid operations and transmission flows with high spatial and temporal resolution. Our detailed simulations affirm the Wind Vision conclusions that effective power system operation can be achieved with wind penetrations above $35 \%$.

Although our analysis identifies no reliability issues in any of the high-wind scenarios, we find that transmission expansion is likely to be critical. Absent significant upgrades to the western transmission network, we find that a substantial amount of renewable energy cannot be utilized by the system, and therefore is curtailed. This curtailment results from an inability to transmit power from where it is generated to where it is needed, and could degrade the potential for wind power to reduce fuel costs and emissions. To assess the value of transmission to mitigate wind curtailment, we model a suite of transmission expansion scenarios. We find that wind curtailment could be reduced by approximately 50\% under a scenario adding $10.5 \mathrm{GW}$ of new transmission, based on four proposed projects (Transmission 1 in Figure E1). This avoided wind curtailment could lower annual production costs and reduce carbon dioxide emissions substantially. Greater transmission expansion was found to yield further benefits, although the marginal benefits of these new lines were found to have diminishing returns (Transmission 2 and 3 in Figure E1). Overall, these results suggest that the power system can be operated with more than $35 \%$ wind penetration (and $12 \%$ solar penetration), but that transmission expansion is necessary to fully utilize the available renewable energy.

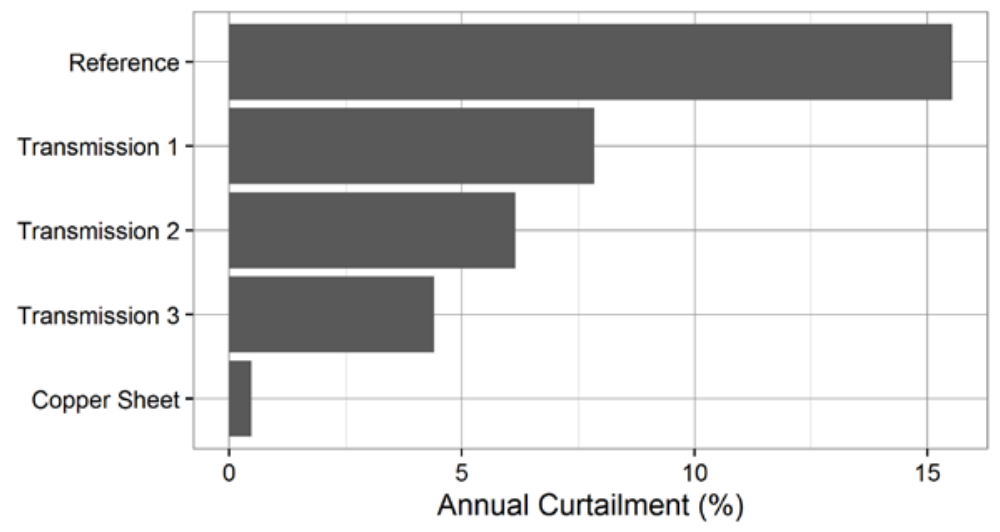

Figure ES-1. Renewable Energy Curtailment Estimated for a Range of Transmission Expansion Scenarios

The figure shows how annual curtailment, in terms of percent of renewable energy that is available but unused, reduces with increasing transmission expansion. The Reference represents the scenario with no transmission beyond what is currently planned; Transmission 1, 2, and 3 represent scenarios with increasing amounts of transmission builds; and Copper Sheet is a bounding scenario with unlimited transmission capacity between nodes. 
Results from and implications of our analysis are summarized as follows:

- Effective power system operation can be achieved with annual wind penetrations greater than $35 \%$.

- This finding helps affirm conclusions from the Wind Vision study that variability is manageable and the grid will be operable under a high renewable energy future.

- High fidelity nodal modeling found no hours of unmet load or unserved reserves. Although this confirms some aspects of grid reliability, this is not a full reliability study, which would include analysis of dynamic stability and frequency response. Other analyses have focused on these questions for high renewable penetrations in the western United States. ${ }^{1}$

- Transmission expansion will play a vital role in allowing for efficient usage of renewable resources.

- Renewable curtailment can be mitigated by transmission expansion. Reducing curtailment also effectively reduces generation costs and carbon dioxide emissions.

- If transmission is not built to support new wind generation in the western United States, significant renewable energy curtailment (15.5\%) could be an issue.

- Curtailment can be reduced by about half (to $7.8 \%$ ) based only on proposed transmission projects.

- Further transmission buildout continues to reduce curtailment and generation costs but with diminishing returns.

- Transmission can provide flexibility for electric power system operation. Inefficient scheduling practices can reduce this flexibility; these practices could include fixed bilateral contracts or the lack of ability to adjust schedules in real-time operations. Inflexibility in transmission scheduling can increase costs and curtailment.

- Grid simulations showed that inflexible transmission utilization could double curtailment levels compared to a scenario with optimal transmission utilization. Generation costs also increased as a result of increased dispatch of fossil-fired units.

\footnotetext{
${ }^{1}$ http://www.nrel.gov/docs/fy15osti/62906.pdf
} 


\section{Table of Contents}

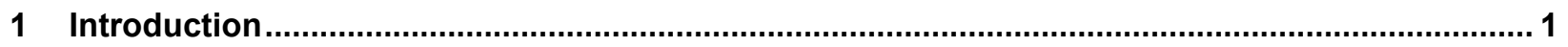

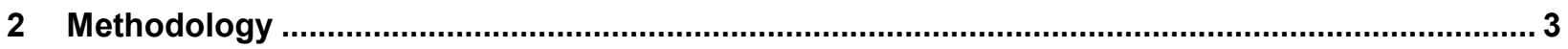

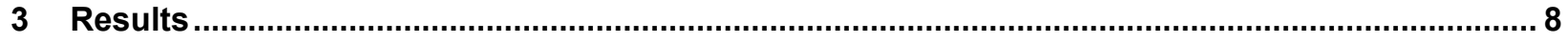

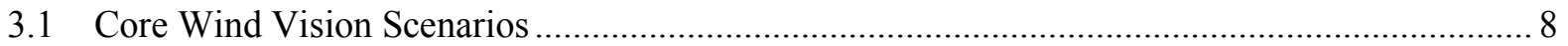

3.1.1 High penetrations of wind energy could lead to high levels of curtailment if the generator fleet and transmission network remain unchanged ...................................... 8

3.1.2 Retiring baseload coal in an unchanged transmission network only reduces curtailment marginally for a high wind penetration scenario....................................................... 11

3.1.3 High wind penetration in a system with no transmission constraints has only $0.5 \%$ curtailment, indicating that transmission capacity is important for the modeled

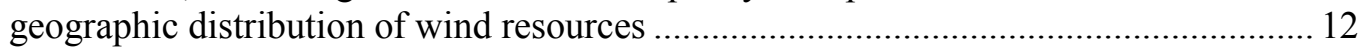

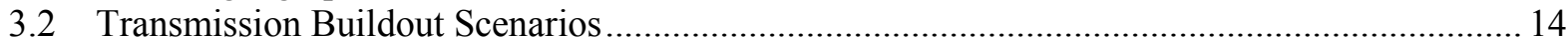

3.2.1 First Transmission Buildout: A small amount of transmission can reduce curtailment

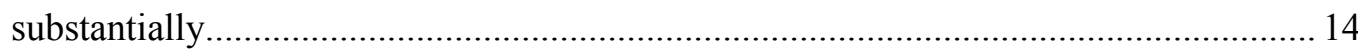

3.2.2 Second Transmission Buildout: Further increasing transmission capacity is useful but

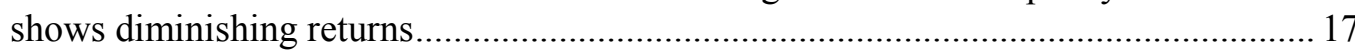

3.2.3 Third Transmission Buildout: A long transmission line directing Rocky Mountain wind toward the West Coast can help reduce wind curtailment ............................................ 18

3.2.4 Cost and emissions results of the transmission buildout scenarios: Transmission can help avoid generation costs and emissions, but with diminishing returns..................... 20

3.2.5 Comparison with ReEDS-generated 2050 Wind Vision Study Scenario....................... 22

3.3 Enforcing suboptimal transmission flows shows the importance of real-time balancing on

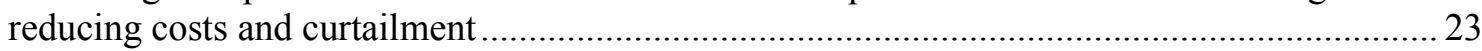

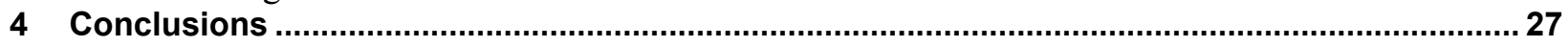

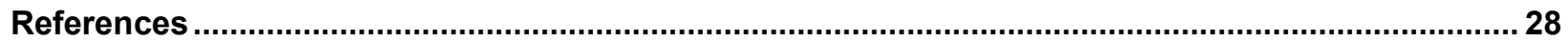




\section{List of Figures}

Figure E1 - Renewable Energy Curtailment Estimated for a Range of Transmission Expansion Scenarios

Figure 1. Progression of day-ahead, intra-day, and real-time simulations in this study ......................... 4

Figure 2. Total wind penetration by state, relative to total state load................................................ 7

Figure 3. Total generation breakdown of the Reference study run (left) compared to the 2050 Wind Vision

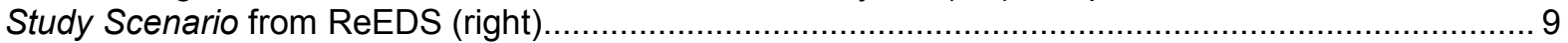

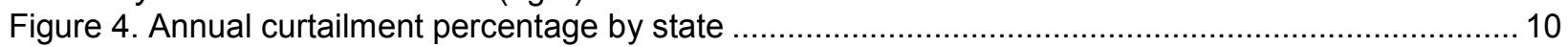

Figure 5. A dispatch stack showing how generation resources are being used in in three seasons ......... 11

Figure 6. Dispatch chart showing the generation mix for three seasons in a system with Wind Vision levels of wind generation and no baseload coal generation ........................................................ 12

Figure 7. Dispatch graph showing the utilization of generation for three seasons in the western United

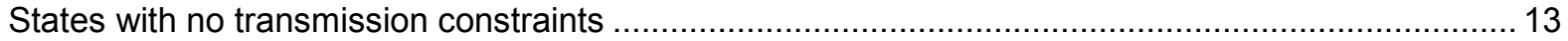

Figure 8. Map of the Transmission 1 buildout, which adds four new lines to wind-heavy states .............. 15

Figure 9. Annual curtailment in each state for the Transmission 1 buildout scenario compared to the

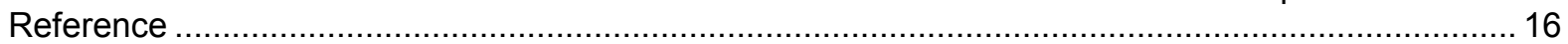

Figure 10. Flow duration cure for four added transmission lines ..................................................... 16

Figure 11. Map of the second transmission buildout, Transmission 2, which includes all four lines from the first buildout, and four more expansions ............................................................................. 17

Figure 12. Map of the third transmission buildout, which includes a direct tie from the Mountain States to

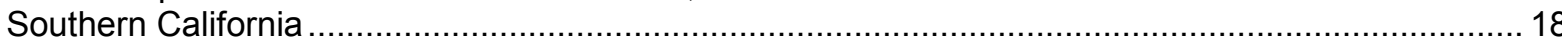

Figure 13. Total annual curtailment in five scenarios ................................................................. 19

Figure 14. Annual imports for each state for the three transmission buildout scenarios compared to the

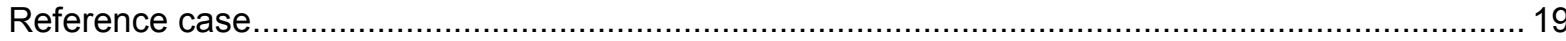

Figure 15. Change in generation in four transmission buildout scenarios compared with the Reference

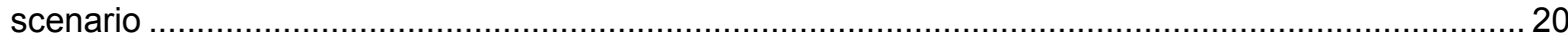

Figure 16. Sample representation of non-optimal flow enforced in this sensitivity ................................2 24

Figure 17. Change in generation in sub-optimal transmission scenarios compared with the Transmission

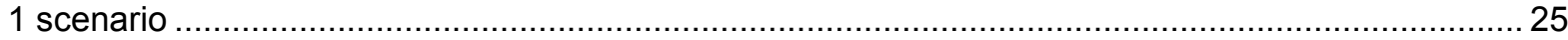

\section{List of Tables}

Table 1. Total Generation in U.S. Western Interconnection as Modeled, By Type .................................. 5

Table 2. Distribution of Wind Resources by State in this Study ...................................................... 6

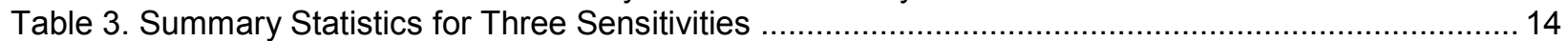

Table 4. Proposed Transmission Projects Modeled in the Transmission 1 Scenario................................ 15

Table 5. Summary of the Cost and Emissions of the Transmission Sensitivities ................................... 20

Table 6. The Sensitivity of Annual Generation Cost on Natural Gas Price ............................................ 22

Table 7. The Savings Associated with Transmission Buildouts under Natural Gas Price Sensitivities...... 22 


\section{Introduction}

Since 2000, wind power has been one of the fastest-growing sources of new generation globally and in the United States. In 2015, wind generation comprised $4.7 \%$ of total U.S. electricity production from nearly 74 gigawatts (GW) of installed capacity (EIA 2016; Wiser and Bolinger 2016). Levels of wind penetration have been much higher in certain regions and over shorter periods. ${ }^{2}$ Declining wind costs and policies that support wind deployment spurred this recent historical growth in U.S. wind power. With this background, the U.S. Department of Energy (DOE) published the Wind Vision study to, among many objectives, explore the cost and benefits of robust wind energy deployment through 2050 (DOE 2015).

In particular, the Wind Vision study evaluated a scenario, referred to as the Wind Vision Study Scenario, in which wind energy served $10 \%$ of end-use electricity demand in $2020,20 \%$ in 2030 , and $35 \%$ in 2050. This scenario was generated using the National Renewable Energy Laboratory (NREL) Regional Energy Deployment System (ReEDS) capacity expansion model (Short et al. 2011; Eurek et al. 2016; Cole et al. 2016). While ReEDS is specifically designed to address many of the issues related to renewable (including wind) grid integration in its scenario decisionmaking, it has a broad scope that necessitates simplifications related to system operations and transmission modeling. For example, ReEDS models power plant dispatch and wind power production using only 17 time-slices in a year. It supplements this reduced resolution dispatch modeling using statistical parameterizations, but it does not perform direct unit commitment and economic dispatch at hourly or sub-hourly resolution akin to practices performed in actual electricity markets or by utility planners.

In this analysis, we seek to better understand the operational implications of scenariosdeveloped based on the Wind Vision Study Scenario - with 35\% wind on the power system. In addition, we evaluate the role of transmission in enabling these high levels of wind. We use a commercially available production cost model, PLEXOS, to model the hour-to-hour, chronological unit commitment and economic dispatch of generators in the Western Interconnection. We model full nodal transmission congestion with unit-level representation of all generators in the Western Interconnection modeling footprint. The detailed modeling framework used in our analysis complements and builds on the modeling conducted in the Wind Vision Study, and confirms the finding from that analysis that the grid can be operated with $35 \%$ wind penetration.

The approach we use in the present analysis is similar to work from many other recent renewable grid integration studies. For instance, NREL studied multiple renewable scenarios up to 33\% wind and solar generation in the western United States and up to 30\% wind and solar in the eastern United States (Lew et al. 2013; Bloom et al. 2016). ${ }^{3}$ GE Energy Consulting also conducted studies of $30 \%$ wind and solar on the PJM balancing area and a state renewable

\footnotetext{
${ }^{2}$ Annual wind penetrations reached $31.3 \%$ (of in-state generation) in Iowa, $25.5 \%$ in South Dakota, $23.9 \%$ in Kansas, and over 10\% in seven other states (Wiser and Bolinger 2016; AWEA 2016). Reported record hourly instantaneous penetration levels for select U.S. regions include $66.4 \%$ by Xcel Energy Colorado, $43.55 \%$ in the Electric Reliability Council of Texas, $42.7 \%$ in the Bonneville Power Administration, 37.8\% in the Southwest Power Pool, and 25\% in the Midwest ISO system (AWEA 2016).

${ }^{3}$ Unless otherwise noted, in this report, we present wind or renewable penetration levels on an annual energy basis relative to total end-use load.
} 
standard of 40\% for Minnesota (GE 2014a, 2014b). Recent studies of high penetrations of renewables (up to and exceeding 50\%) for California focus on solar integration; however, high wind energy shares serving California or across the western United States are also often prevalent in the studies (Brinkman et al. 2016; Nelson and Wisland 2015; E3 2014). However, fewer detailed analyses of scenarios with higher penetrations of wind (35\% or greater) that are similar to those from the Wind Vision Study Scenario have been published. Notable exceptions include the Renewable Electricity Futures study (Mai et al. 2012), which included (1) scenarios with nationwide penetrations wind and solar photovoltaics (PV) of about $50 \%$ and (2) hourly modeling using the GridView production cost model but used only a simplified zonal transmission modeling. Brinkman (2015) used PLEXOS sub-hourly modeling to evaluate scenarios, based on the Renewable Electricity Futures analysis, with up to about $35 \%$ wind penetration (plus 17\% solar penetration) in the Western Interconnection. However, this operational analysis de-emphasized transmission by also using simplified zonal transmission modeling. MacDonald et al. (2016) used hourly modeling to generate a carbon-mitigation scenario with 38\% wind penetration in the United States and a nationwide high-voltage transmission network. However, due to their modeling scope (the entire United States with capacity expansion coupled to hourly dispatch), MacDonald et al. (2016) used more-simplified representations of system operations and the transmission network.

This large body of recent renewable grid integration research has resulted in a remarkably consistent key conclusion: integrating high shares of wind power is technically achievable but will require changes to operating practices. The literature also indicates that curtailment becomes an increasingly important issue with higher penetration shares (Denholm and Margolis 2016; Denholm 2016). Relatedly, the literature suggests that transmission expansion is one option to increase system flexibility and thereby mitigate curtailment and other integration challenges. Other options include improving regional coordination, diversifying the resource mix, improving flexibility of the existing generator fleet, or adding demand response or storage. Our current analysis builds on this large body of work and specifically examines the operational viability of the Wind Vision Study Scenario. It also focuses on the impacts of transmission expansion within the context of this $37 \%$ wind (with $12 \%$ solar PV) scenario. ${ }^{4}$

\footnotetext{
${ }^{4}$ The Wind Vision Study Scenario for 2050 has 35\% wind penetration and 9\% solar PV penetration for the entire contiguous U.S. Since we are modeling the Western Interconnection only (see Section 2), we have slightly higher total wind and PV levels.
} 


\section{Methodology}

In this work, we model the operation of the power system to understand the challenges associated with the very high wind penetration analyzed in the DOE's 2015 Wind Vision study. We use PLEXOS, a commercial unit commitment and economic dispatch model to analyze a scenario based on the Wind Vision Study Scenario in 2050. This first Reference run assesses the feasibility of the wind portfolio in a scenario with few upgrades to the transmission or generator profile. Next, we model sensitivities to discern the primary drivers of integration issues in that high wind scenario. Finally, we evaluate three transmission buildout scenarios and include a sensitivity to evaluate sub-optimal usage of transmission capacity.

In this section, we summarize the methods used in the PLEXOS model. The data and assumptions used in the modeling are largely based on the cited studies. We also describe the high wind scenario constructed for the PLEXOS analysis and modeled after the Wind Vision Study Scenario. Although the Wind Vision study includes the entire contiguous United States, we consider only the Western Interconnection, which spans most of 11 Western states, two Canadian provinces, and small regions in northern Mexico. This simplification reduces the computational run time substantially and allows more flexibility in designing scenarios while still enabling conclusions based on the operation of a large realistic bulk power system.

Using PLEXOS, we simulate day-ahead, intra-day, and real-time operations, as represented in Figure 1. The day-ahead simulation uses day-ahead forecasts for wind and solar generation. Because some generators require long start-up times, this simulation step determines the commitment status, or whether a generator is on or off, for the large slow-starting generators (e.g., coal generators). This first simulation step also determines the dispatch of hydropower and storage generators. Next, the intra-day simulation uses the coal dispatch and storage/hydro dispatch from the day-ahead, with four-hour-ahead forecasts for wind and solar energy. This simulation step determines the commitment of intermediate load generators (e.g., natural gas combined-cycle [gas CC] generators). The commitment status of the coal (determined in the dayahead) and of the gas CCs (determined in the intra-day) feeds into the real-time simulation, which commits the quick-start generators (e.g., gas combustion turbines [gas CTs]) and sets the final dispatch of the entire generator fleet. Thus, the results presented in this report represent the final real-time dispatch of the system, which incorporates forecast error for wind and solar energy. 


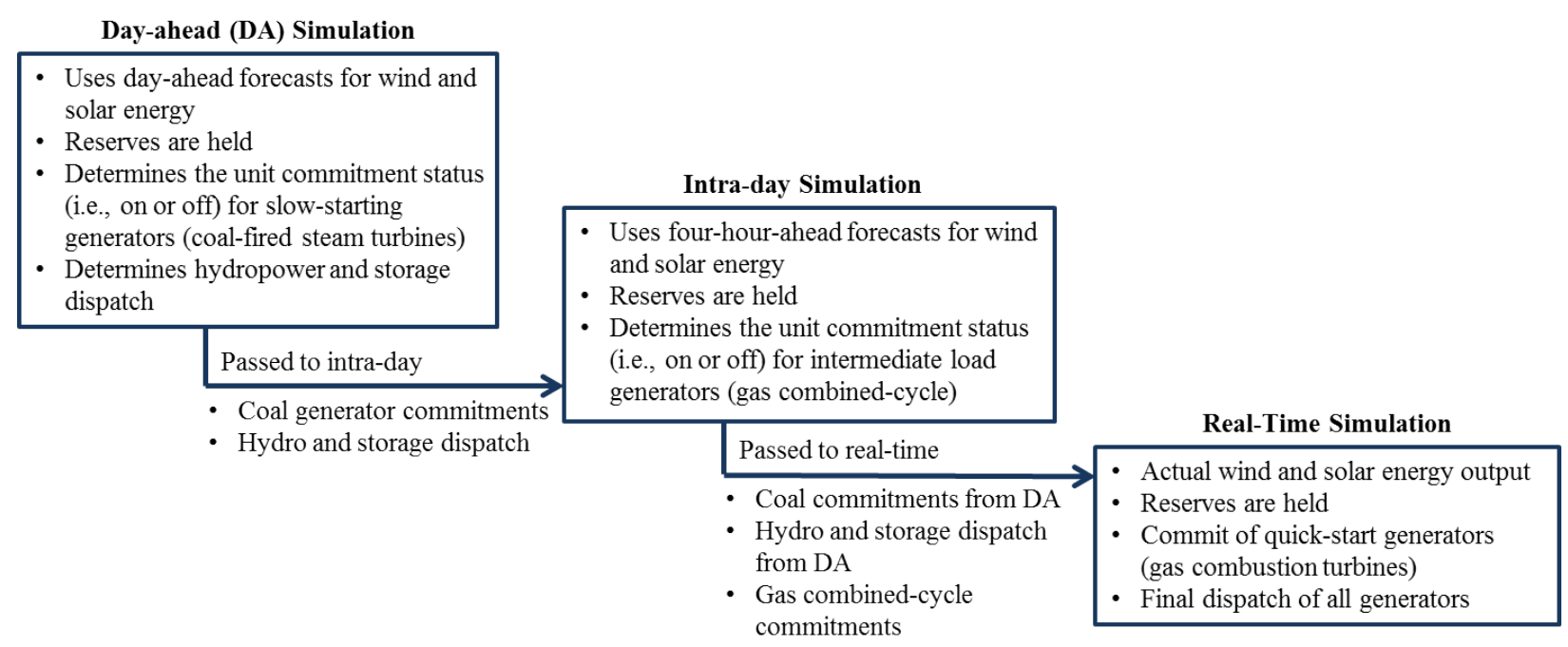

Figure 1. Progression of day-ahead, intra-day, and real-time simulations in this study

The PLEXOS data set for this study is derived from the Western Electricity Coordinating Council (WECC) Transmission Expansion Planning Policy Committee (TEPPC) 2024 Common Case database (WECC 2015). This database contains generator information for all generators in the Western Interconnection, as well as transmission network topology. We model nodal transmission congestion and enforce 118 transmission paths with flow limits based on the TEPPC 2024 stakeholder review process ${ }^{5}$. The transmission network represents existing transmission and some builds with "high expectation of being in service" by 2024. Furthermore, we adopt data set changes associated with the modeling in the High West scenario of the California 2030 Low Carbon Grid Study (Brinkman et al. 2016).

However, we make further generator fleet changes to align the model more closely with the Wind Vision Study Scenario in 2050, which was constructed using the ReEDS capacity expansion model. These changes include retirement of all nuclear generators, increased PV energy, and much higher wind generation. To be clear, we do not attempt to align the generator or transmission capacity modeled in PLEXOS with that in the ReEDS scenario due to data and time constraints. Instead, we simply attempt to match the west-wide wind and PV penetration levels, generate a somewhat consistent geographic distribution of the wind capacity from the ReEDS scenario, and eliminate the nuclear capacity as is consistent with the ReEDS 2050 scenario. The amount and distribution of other generator capacity, including coal, natural gas, and storage, as well as the amount and location of new transmission also differ between the ReEDS Wind Vision Study Scenario and the PLEXOS scenario presented herein. Table 1 shows the resulting total generation capacity by type.

\footnotetext{
${ }^{5}$ WECC path limits could be different in the future due to generator retirements, infrastructure changes, etc.
} 
Table 1. Total Generation in U.S. Western Interconnection a as Modeled, By Type

\begin{tabular}{lc}
\hline Type & Capacity (GW) \\
\hline Biomass & 2.5 \\
\hline Coal & 27 \\
\hline Concentrating solar power (CSP) & 3.2 \\
\hline CSP with thermal energy storage (CSP-TES) & 2.8 \\
\hline Gas CC & 56 \\
Gas CT & 29 \\
\hline Geothermal & 4.2 \\
\hline Hydro & 49 \\
\hline Other (combined heat and power, engines, steam turbines) & 6.2 \\
\hline PV & 49 \\
\hline Customer-sited PV & 13 \\
\hline Energy Storage (pumped hydro, battery) & 5.6 \\
\hline Wind & 116 \\
\hline Total (sum) & 366 \\
\hline Peak Load & 188 \\
\hline Total Annual Load & 1,030 terawatt- \\
\hline hour (TWh) \\
\hline Interconnection, which includes Alberta and British Columbia in western Canada and a small \\
amount of Mexico. Although we model the full footprint, we focus on results for only the U.S. portion \\
of the interconnection, including Table 1. \\
\hline
\end{tabular}

The profiles for wind and solar generation originate from the data set developed for the Western Wind and Solar Integration Study, Phase 2 (Lew et al. 2013). The profiles include wind, solar PV, and concentrating solar power (CSP) forecasts for the day-ahead and intra-day, as well as the real-time actual generation data. We use coincident 2006 data for load, wind, and solar profiles, with the load data grown based on information from the Energy Information Administration Annual Energy Outlook. We adopt assumptions from the High West scenario from the California 2030 Low Carbon Grid Study to determine locations for solar PV and CSP generators. However, we base the amount and geographic distribution of wind generation on the Wind Vision Study Scenario. In that scenario, deployed wind in 2050 reaches 371 terawatt-hours (TWh) of annual wind generation for the western United States, which serves about 1,000 TWh of total demand. Of this wind generation, about $70 \mathrm{TWh}$ originates from offshore wind, ${ }^{6}$ and the rest $(301 \mathrm{TWh})$ originates from land-based wind. Due to a shortage of offshore wind sites in the wind data set utilized here, we model $35 \mathrm{TWh}$ of offshore wind and distribute the remaining 35 TWh to land-based resources. Likewise, we are unable to model an identical geographical distribution of wind in the western states compared to the distribution from the Wind Vision Study Scenario. However, the scenario modeled here, shown in Table 2, does capture the magnitude and general distribution of wind resources represented in the Wind Vision Study Scenario.

${ }^{6}$ Offshore wind builds were prescribed for the Wind Vision Study Scenario, meaning that a certain amount of offshore wind would be developed regardless of economic considerations. 
Table 2. Distribution of Wind Resources by State ${ }^{a}$ in this Study

\begin{tabular}{|c|cccc|cc|}
\hline State & $\begin{array}{c}\text { Offshore } \\
\text { Wind } \\
\text { (MW) }\end{array}$ & $\begin{array}{c}\text { Offshore } \\
\text { Wind } \\
\text { (Annual } \\
\text { TWh) }\end{array}$ & $\begin{array}{c}\text { Onshore } \\
\text { Wind } \\
\text { (MW) }\end{array}$ & $\begin{array}{c}\text { Onshore } \\
\text { Wind } \\
\text { (Annual } \\
\text { TWh) }\end{array}$ & $\begin{array}{c}\text { Solar PV } \\
\text { Generation } \\
\text { (Annual } \\
\text { TWh) }\end{array}$ & $\begin{array}{c}\text { Load } \\
\text { (Annual } \\
\text { TWh) }\end{array}$ \\
\hline Arizona & - & - & 5,050 & 13.4 & 15.0 & 118 \\
California & 6,510 & 22.0 & 13,500 & 36.8 & 66.6 & 410 \\
Colorado & - & - & 9,360 & 30.5 & 9.59 & 63.2 \\
Idaho & - & - & 3,000 & 8.05 & 1.22 & 28.3 \\
Montana & - & - & 20,900 & 67.6 & 0.669 & 17.9 \\
\hline Nevada & - & - & 3,080 & 8.78 & 7.26 & 49.3 \\
New & - & - & 9,120 & 31.0 & 4.92 & 33.6 \\
Mexico & - & 3.45 & 8,540 & 25.1 & 4.08 & 91.2 \\
\hline Oregon & 838 & 3.45 & 4.62 & 5.06 & 46.6 \\
Utah & - & - & 1,610 & 4.62 & 115 \\
Washington & 2,090 & 9.47 & 8,337 & 21.9 & 5.25 & 57.3 \\
Wyoming & - & - & 24,400 & 91.1 & 0.808 & $\mathbf{1 , 0 3 0}$ \\
\hline Total & $\mathbf{9 , 4 4 0}$ & $\mathbf{3 5 . 0}$ & $\mathbf{1 0 7 , 0 0 0}$ & $\mathbf{3 3 9}$ & $\mathbf{1 2 0}$ & \\
\hline
\end{tabular}

a Some states in Table 2 are not fully contained in the Western Interconnection (i.e., Montana and New Mexico) and thus the table includes only portions of states that fall into the footprint of the Interconnection.

Figure 2 (next page) shows the average wind penetration (possible annual wind generation as a percentage of annual load) for each state. The figure also depicts the maximum instantaneous penetration of wind in each state, which considers every hour of the study year and the highest possible percentage of load which could be met by available wind, before any curtailment. Many of the highest-quality wind resources are in the Mountain States, ${ }^{7}$ which generally have lower energy demand than the coastal states. The figure indicates that a large amount of wind generated in states such as Montana and Wyoming will need to serve load in other states in order to fully utilize the resource. For the whole West, our modeled scenarios include 37.4\% potential wind energy of 1,030 TWh of annual electricity consumption. The scenarios also include $12.0 \%$ potential solar energy.

The burner-tip natural gas price as modeled averages $\$ 6.7$ per million British thermal units (MMBtu). This price is originally derived from the Energy Information Administration (EIA) mid-case Annual Energy Outlook (AEO) 2014 Reference projection of the Henry Hub price in 2030 (EIA 2014). We use the California Public Utilities Commission RPS Calculator to determine adders for electricity generation the original Henry Hub price (CPUC 2016). Additionally, the natural gas price varies by both region and month of the year as implemented in the WECC TEPPC Common Case. For instance, natural gas prices are generally most expensive in the winter months due to increased demand from other sectors and end-uses (e.g., heating). Regionally, natural gas is the most expensive in California and the least expensive

\footnotetext{
${ }^{7}$ Here we refer particularly to Montana, Wyoming, Colorado, and New Mexico.
} 
in the Mountain States. Coal prices, like natural gas prices, vary regionally but average about \$2/MMBtu. Recognizing the significant uncertainties in natural gas prices, we calculate how our resulting production costs might vary with a different set of natural gas prices (see Section 3.2.4).

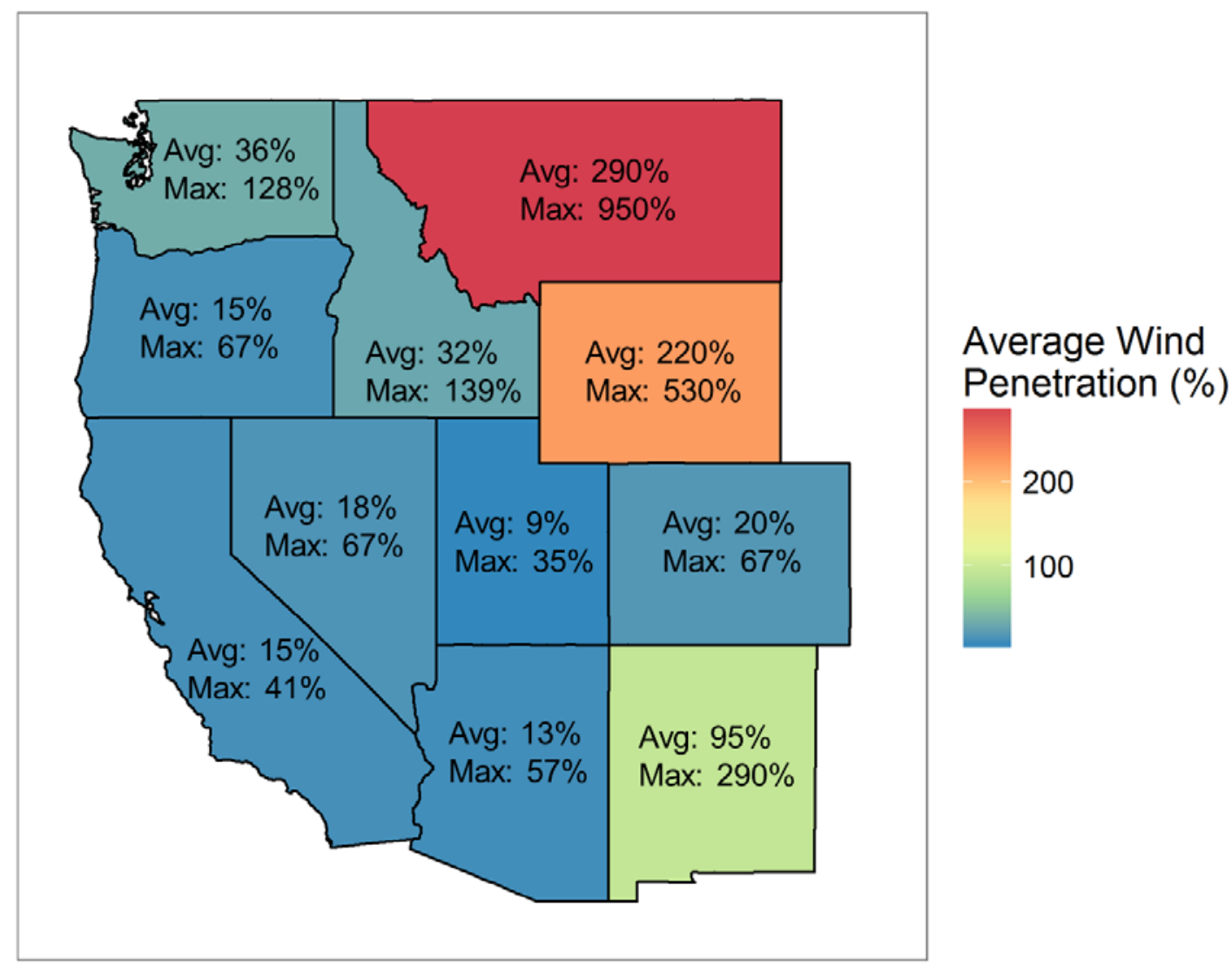

Figure 2. Total wind penetration by state, relative to total state load

Numbers represent potential wind generation before curtailment. 


\section{Results}

Results of this study are organized into three sections. First, we discuss the results of the Reference simulation in Section 3.1, which models the wind portfolio shown in Figure 2 as well as simulations to identify the key drivers of curtailment. In Section 3.2, we analyze the same wind portfolio with transmission upgrades to determine the effect of new transmission on curtailment and generation costs. Finally, we assess the influence of sub-optimal transmission scheduling in Section 3.3.

\subsection{Core Wind Vision Scenarios}

Previous studies have examined how large shares of variable generation (VG) such as wind and solar complicate the operating paradigm of the power grid. Firstly, variable generation is a nearzero marginal cost resource as its fuel is free. Secondly, variable generation is weather dependent and thus uncertain and variable in its output. Given these properties, grid operators have economic incentives to use variable generation resources as much as possible, but they must accommodate the generation by reducing output from another resource. Under various circumstances, energy from variable generation resources cannot be accommodated, and curtailment results. Curtailment represents loss of a zero-marginal cost resource because it is more economical to spill the energy than to use it.

Curtailment can have many causes, including insufficient transmission capacity (congestion) or the inability to reduce output from other generating sources (Bird, Cochran, and Wang 2014; Denholm et al. 2015). Effectively operating a system with higher shares of wind and solar while minimizing curtailment may require infrastructure changes, such as increased transmission capacity or more flexible, fast-start generation sources such as gas-fired combustion turbines. In this report, the reported curtailment represents potential energy from any variable generation resource, including wind, solar PV, and CSP without thermal storage.

\subsubsection{High penetrations of wind energy could lead to high levels of curtailment if the generator fleet and transmission network remain unchanged}

To assess whether increased penetrations of wind and solar require major changes to infrastructure, ${ }^{8}$ we first add the high levels of wind (37\%) and solar (12\%) described in Section 2 to a system without major infrastructure changes relative to the grid as modeled in the 2024 TEPPC Common Case. ${ }^{9}$ This scenario is referred to as our "Reference" scenario. The right bar in Figure 3 (next page) indicates the total generation breakdown as a result of simulating this Reference scenario (left) and compares it to the total generation breakdown of the western United States in the 2050 Wind Vision Study Scenario from ReEDS (right). At a high level, the figure indicates that the breakdown of generation is similar; the annual amounts of generation from coal-fired, natural gas-fired, and other generators are largely consistent between the two scenarios, which suggests that the dispatch economics captured by ReEDS and PLEXOS are

\footnotetext{
${ }^{8}$ Here we study a single renewables buildout, focusing on the 2050 Wind Vision Study Scenario. Other buildouts that prioritize local resources, rather than the "optimized" buildout from the ReEDS model could look substantially different and may show different integration issues than we analyze here.

${ }^{9}$ Although the modeled version of the grid does not, of course, perfectly represent a future grid, it does represent stakeholder-vetted assumptions regarding the operation of the transmission and generator system for the studied year.
} 
largely consistent. The small differences are largely caused by differences in capacity as the fleets in the two analyses were not identical.

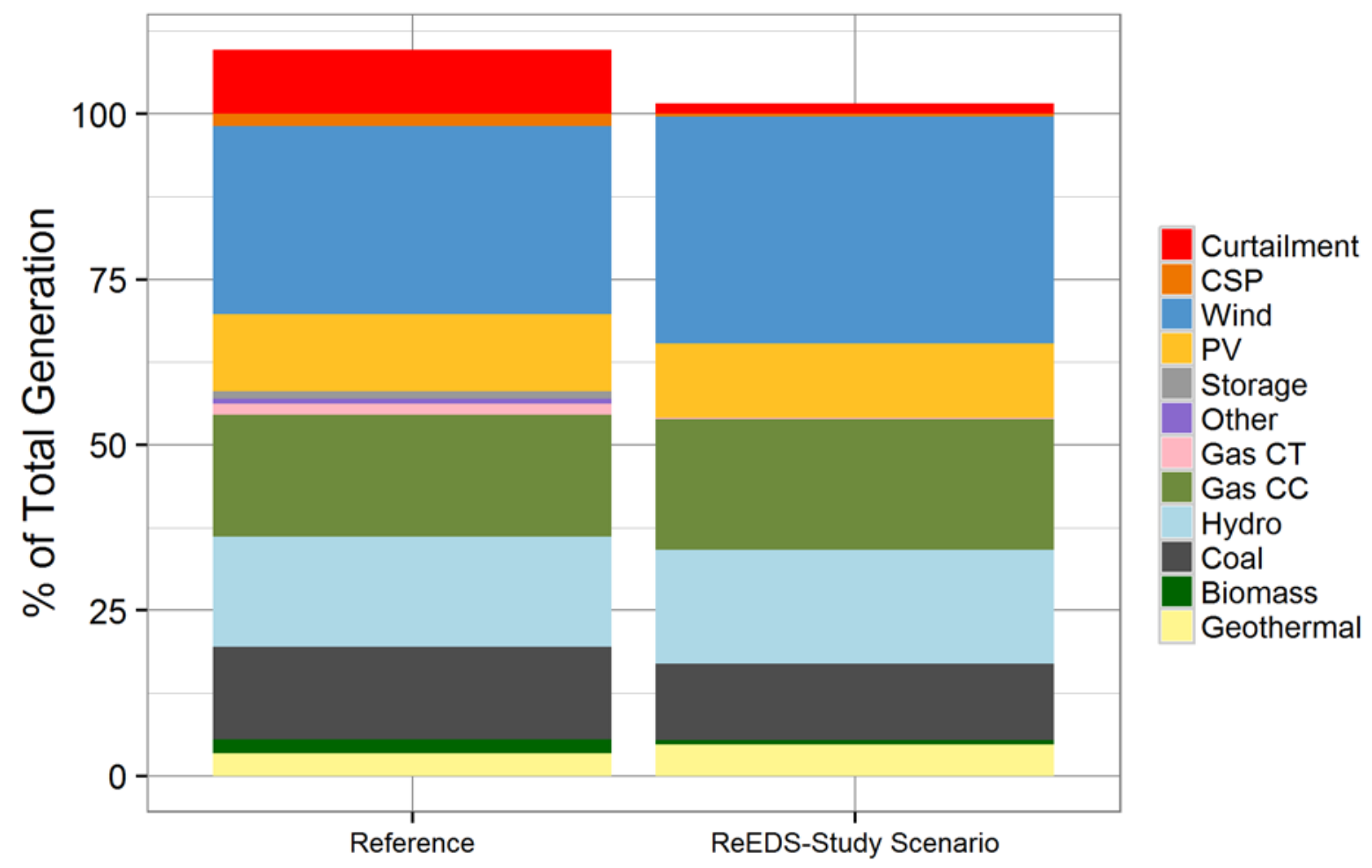

Figure 3. Total generation breakdown of the Reference study run (left) compared to the 2050 Wind Vision Study Scenario from ReEDS (right)

As is apparent from Figure 3, one major difference between the Reference scenario and ReEDS results is the level of curtailment. Curtailment of renewable resources (in red) is much higher in this Reference simulation compared to the 2050 Wind Vision Study Scenario. To explain this difference, we first consider the differences between this study and the Wind Vision study.

The Wind Vision study utilized a capacity expansion model, NREL's ReEDS model, to determine the efficacy of a high wind future in 2050. Capacity expansion models are used as planning tools to consider the long-term effects and economics of generation and transmission procurement into the future. Because their modeling covers many years-decades in the case of ReEDS - the operation and dispatch of the system on an hour-by-hour basis is simplified in order to make the long-term solve horizon tractable. ReEDS includes statistical methods to estimate renewable capacity value, forecast error requirements, and curtailment to better inform the investment and dispatch decisions in the model. However, these methods and their underlying data cannot fully replace the hourly unit commitment and dispatch modeling. Thus, the simplified representation of power system operations could cause ReEDS and other planning models to imperfectly represent the challenges of operating a high-wind power system. Additionally (and perhaps more relevantly), the ReEDS model simultaneously optimizes generation and transmission capacity, meaning the Wind Vision study runs incorporate additional transmission builds as well as generator fleet retirements that affect system dispatch. As mentioned, we do not incorporate any additional transmission associated with the new wind 
capacity in our Reference scenario. Nor do we yet account for generator retirements that may affect the flexibility of the overall power system. For these reasons, this study observes a much higher initial curtailment rate $(15.5 \%)$ in the Reference scenario than the ReEDS-estimated curtailments (3\%) do in the 2050 Wind Vision Study Scenario.

Figure 4 indicates the state in which curtailment takes place in PLEXOS simulations compared to the 2050 Wind Vision Study Scenario runs in ReEDS. As discussed previously, the ReEDS model simultaneously builds out generation and transmission capacity, meaning that the ReEDS curtailment numbers include new transmission. However, the PLEXOS simulations have only today's transmission with a few expected builds between now and 2030, and no new transmission associated with the new wind generation. The plot in Figure 3 indicates while the ReEDS curtailment is relatively distributed throughout the West, the PLEXOS-estimated curtailment for the Reference scenario occurs at high levels in Montana, New Mexico, and Wyoming where wind penetration is the highest. These results also show that renewable curtailment in the states that are farther west - including Arizona, California, Idaho, Oregon, and Washington - are small despite high annual and instantaneous penetrations in many of these states.

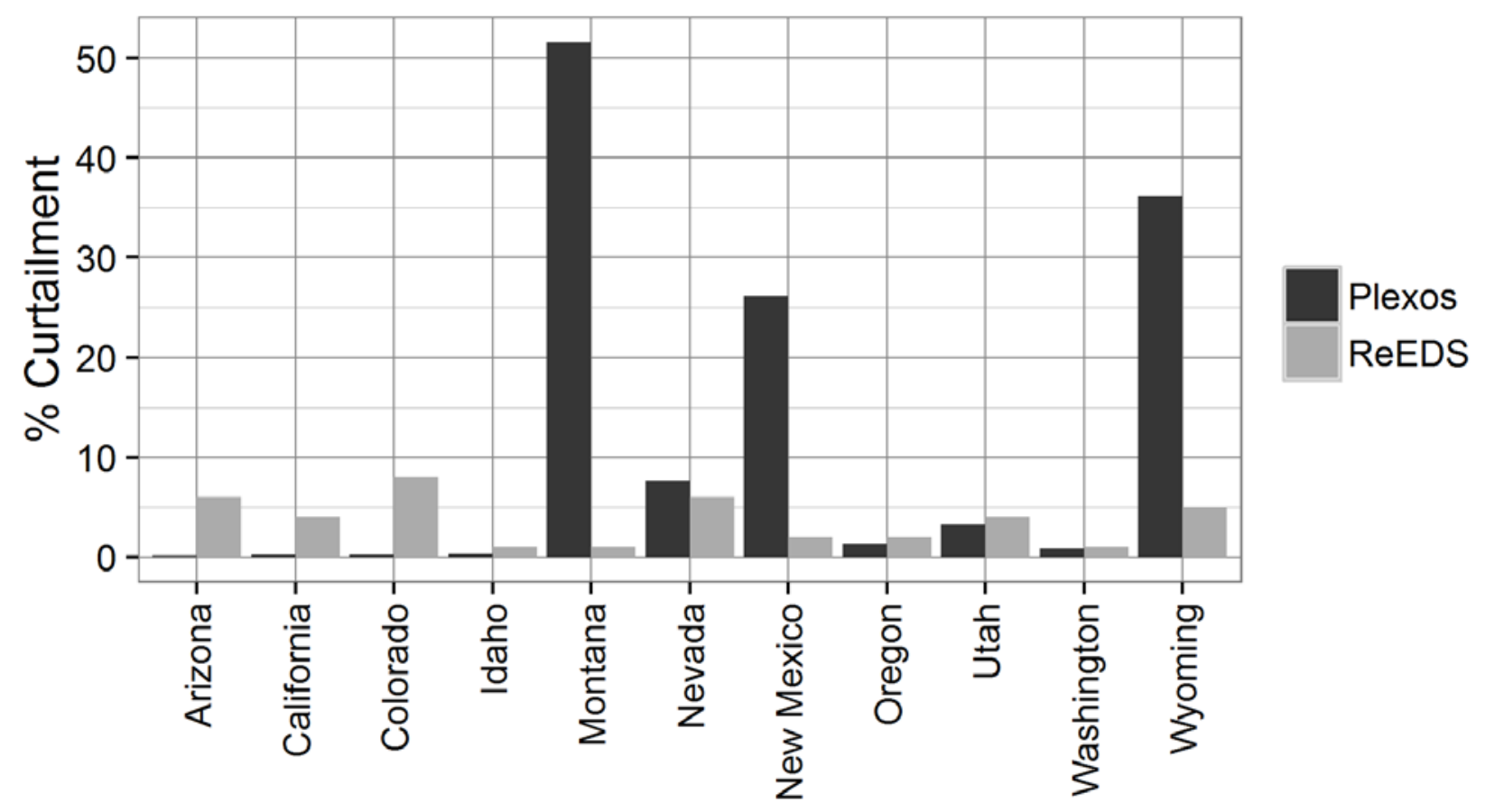

Figure 4. Annual curtailment percentage by state

ReEDS results consider transmission expansion endogenously modeled whereas the PLEXOS results reflect no transmission builds beyond 2030.

Even with higher levels of curtailment, we do see an effective integration of relatively high levels of wind and solar generation, as illustrated in Figure 5. The figure shows the dispatch of the generators in the system for six days in three seasons, as well as curtailed energy. The graph indicates lower curtailment in the summer when energy demand is higher, and higher curtailment in the winter and spring seasons. The plot also shows expensive gas generation (for instance, gas 
CTs) generating at times even during curtailment. This could indicate an inability to effectively use wind renewable generation to displace the most expensive generating resources due to locational aspects of the transmission network. Furthermore, the two spring dispatch days show coal generation remaining generally flat despite higher curtailment on the second day. Because coal plants are often large and inflexible, the failure of coal plants to turn off to accommodate more wind and solar on the second spring day could result from the long start-up and ramp time required to bring coal plants back online after a shutdown.

The results of the Reference scenario indicate that without new transmission, the wind capacity deployed in the Wind Vision scenarios faces significant curtailment. Although the Wind Vision Study Scenario indicates an achievement of 37\% wind penetration in the western United States (with around $12 \% \mathrm{PV}$ penetration) by 2050 , this Reference run only achieves $28 \%$ wind due to the curtailment. The simulation indicates insufficient transmission capacity, a generator fleet with insufficient flexibility, or both. To assess the relative impacts of transmission or generator inflexibility on curtailment, we run one simulation with a retired coal fleet to show the effects of a more flexible generator fleet (Section 3.1.2) and one simulation with no transmission constraints (Section 3.1.3).

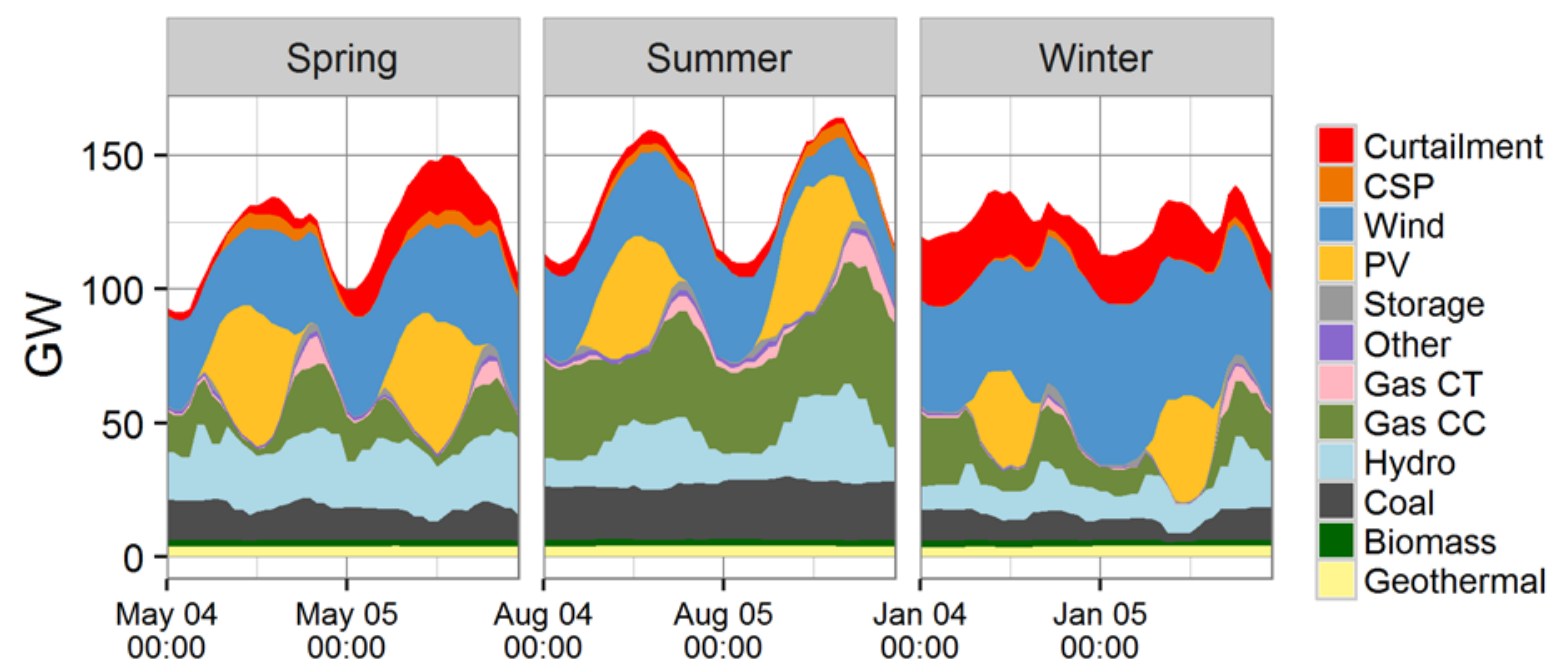

Figure 5. A dispatch stack showing how generation resources are being used in in three seasons

\subsubsection{Retiring baseload coal in an unchanged transmission network only reduces curtailment marginally for a high wind penetration scenario}

Coal generators are generally large and require hours or days to start-up after being shut down. Once they are online, they can only turn down $40 \%-60 \%$ of their maximum capacity. In this first sensitivity, we remove all coal generation from the same high wind system as in the Reference scenario to see whether the inflexible generator fleet is restricting wind energy integration. Figure 6 shows the dispatch for the same six days as Figure 5. A comparison of the two figures shows that Gas CC and Gas CT generation largely makes up for the deficit in coal generation. However, the level of curtailment for these days looks largely unchanged. In fact, retiring the coal generation fleet reduces curtailment only marginally, from $15.5 \%$ to $14.9 \%$. This small difference indicates that baseload coal is not significantly causing the observed curtailment. 


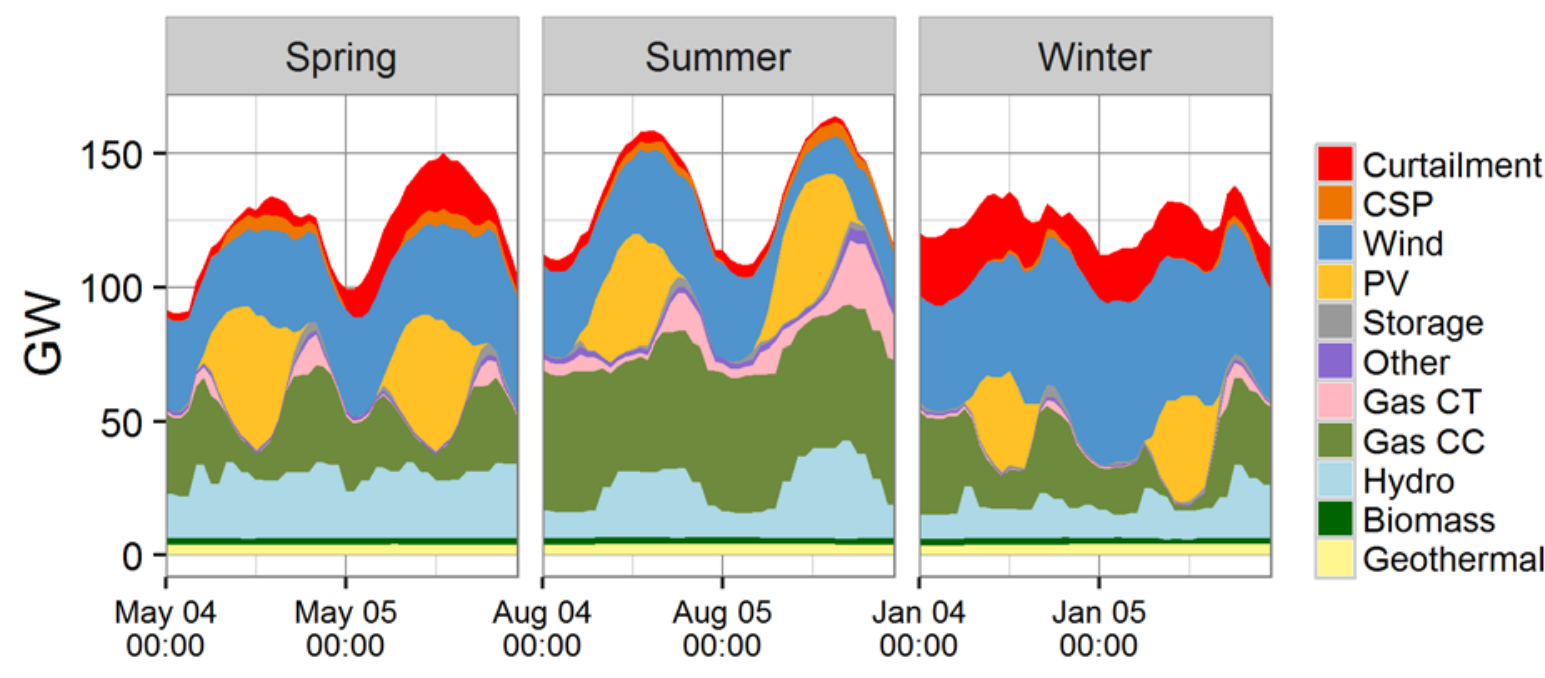

Figure 6. Dispatch chart showing the generation mix for three seasons in a system with Wind Vision levels of wind generation and no baseload coal generation

This result is likely caused by the fact that coal generation can still turn down (to a certain extent) and off in the case of high amounts of available renewable energy. ${ }^{10}$ Wind energy, in particular, often exhibits seasonal patterns, which provides coal generators enough "warning" to turn off during the windiest days and weeks. Furthermore, we see in Figure 6 that coal generation disappears but is often replaced by gas instead of curtailed wind generation. This could indicate that locational aspects, for instance where wind generators are located on the transmission network, are playing a bigger factor in driving curtailment.

\subsubsection{High wind penetration in a system with no transmission constraints has only $0.5 \%$ curtailment, indicating that transmission capacity is important for the modeled geographic distribution of wind resources}

The best wind resources in the western United States are often not near the most populated regions. Therefore, taking full advantage of the wind in the western United States may require transporting wind hundreds of miles from where it is generated to where it is needed. To determine the relative importance of adequate transmission, we simulate a scenario with Wind Vision levels of wind in the western United States with no transmission constraints. In other words, the energy flows as readily as it would on a "copper sheet."11

Figure 7 shows the dispatch of the system under no transmission constraints. We notice a much lower level of curtailment in every season. In fact, annual curtailment is reduced from $15.5 \%$ under the Reference to $0.5 \%$ in this Copper Sheet scenario. A comparison of Figure 7 and Figure 5 also shows more efficient use of the generator fleet in general. For instance, less gas generation is online in the spring, which allows lower-cost coal and wind generation into the stack. The summer shows a flat, baseload profile of coal output and reduced usage of the expensive Gas CT

\footnotetext{
${ }^{10}$ We should note, however, that the modeled coal fleet may exhibit more flexibility than reality. For instance, we do not model energy contracts that could result in a reduced ability for coal generators to turn off or down.

${ }^{11}$ The Copper Sheet scenario assumes there are no limits to how much power can flow on any line throughout the model.
} 
peaker plants, especially on the second summer day. The winter days show very high amounts of wind energy, which is largely accommodated by a reduction in output from the Gas CC fleet. We also see that eliminating transmission constraints results in coal generators providing more obvious net load-following, reducing their output during the daytime hours (when solar PV comes online) and increasing output in the evening to help with peak load. This illustrates that the coal generation fleet, as modeled, can be relatively flexible, but that transmission constraints play a part in reducing the extent of coal flexibility.
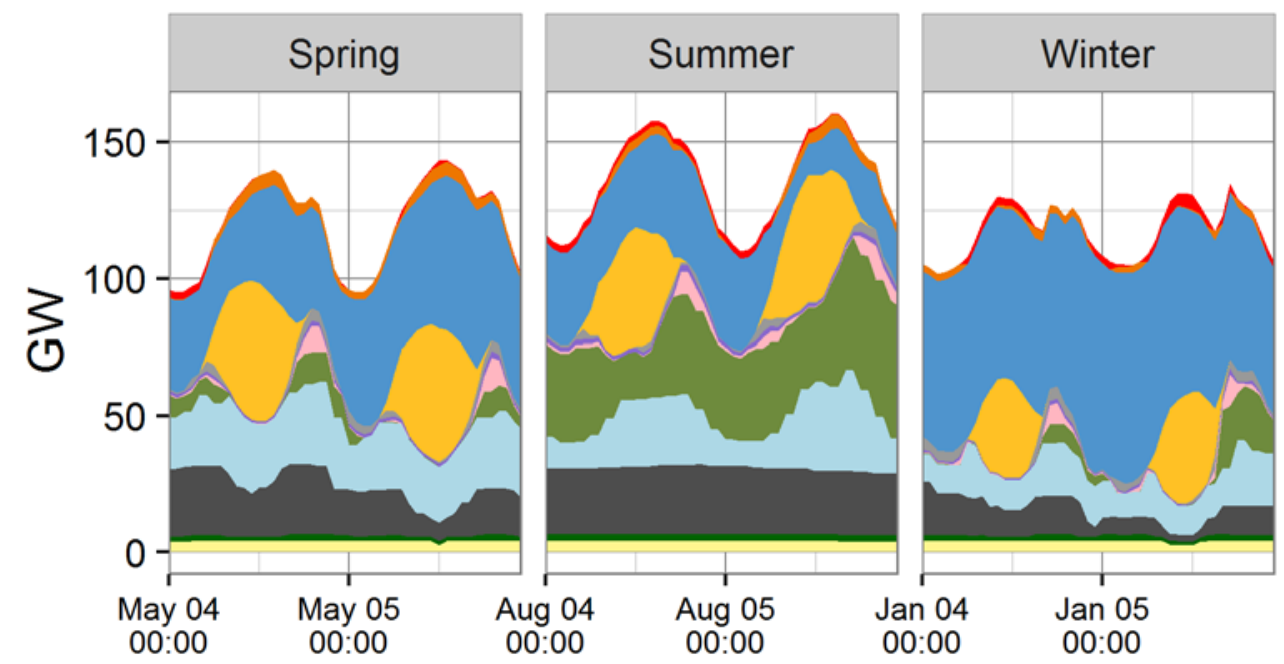

Curtailment

CSP

Wind

PV

Storage

Other

Gas CT

Gas CC

Hydro

Coal

Biomass

Geothermal

Figure 7. Dispatch graph showing the utilization of generation for three seasons in the western United States with no transmission constraints

This scenario suggests that transmission congestion is the primary cause of curtailment observed in the Reference scenario. This result is unsurprising, given the geographical separation of the modeled wind and load. Conversely, coal generator inflexibility does not appear to have a major impact on curtailment. Table 3 summarizes the results from these first three sensitivities. The annual total generation cost (in billions of dollars) represents the sum of generator fuel costs, start and shutdown costs, and variable operation and maintenance costs. Note that the generation cost does not include capital costs or fixed costs, meaning that the values from Table 3 are insufficient for a benefit-to-cost analysis ${ }^{12}$. The Copper Sheet scenario reduces generation costs by $\$ 5.3$ billion annually, or about $28 \%{ }^{13}$ by enabling the use of the lower marginal cost resources (wind and coal) and displacing the more expensive resources (gas). Even though coal generation increases in the Copper Sheet scenario relative to the Reference case, annual carbon dioxide emissions decrease due to the increased use of wind energy, which displaces fuel-burning technologies. The Retirements case has both the highest total generation costs (due to retirement of coal, the least expensive fossil fuel source) and the lowest annual carbon emissions (due to

\footnotetext{
${ }^{12}$ Although we do not include capital or fixed costs, the original capacity expansion modeling for Wind Vision which inspired this analysis does consider both cost and value when determining the future buildout. For more information, refer to the Wind Vision study (DOE 2015).

${ }^{13}$ Although the Copper Sheet scenario reduces costs by a significant percentage, it is important to note that an actual implementation of this scenario in the real world would be impossible (infinitely expensive) due to the capital costs needed to realize the modeled transmission infrastructure. Therefore, this scenario is simply meant to determine underlying causes of curtailment, not to present a potential path forward for wind integration or to provide a reasonable estimate of generation cost savings.
} 
retirement of coal, the highest-emitting source). The Retirements case does not show a reduction in annual curtailment and therefore did not take advantage of the benefits of zero marginal cost and emission wind energy, so the change in annual carbon emissions is almost entirely from switching generation from coal to gas. As seen in Figure 7, the grid as modeled for this scenario did not have many flexibility challenges, probably due to the cooperation between regions that is assumed in the modeling. For more detailed analysis of this issue, see section 3.3.

Table 3. Summary Statistics for Three Sensitivities

\begin{tabular}{llll}
\hline Scenario & $\begin{array}{l}\text { Total Generation Cost } \\
\text { (\$billion/yr) }\end{array}$ & $\begin{array}{l}\text { Annual Curtailment } \\
\mathbf{( \% )}\end{array}$ & $\begin{array}{l}\text { Annual Carbon Dioxide } \\
\left(\mathbf{C O}_{2}\right) \mathbf{( M M T )}\end{array}$ \\
\hline Reference & 19.6 & 15.5 & 308 \\
Retirements & 23.6 & 14.9 & 222 \\
Copper Sheet & 14.3 & 0.5 & 293 \\
\hline
\end{tabular}

\subsection{Transmission Buildout Scenarios}

The results of the first three sensitivities, shown in Table 3, indicate that the modeled transmission capacity is unable to accommodate the high levels of wind, particularly from wind in the Mountain States. Next, we model three transmission expansion scenarios to determine the amount and value of transmission that may be required to effectively transport Wind Vision levels of wind throughout the West.

\subsubsection{First Transmission Buildout: A small amount of transmission can reduce curtailment substantially}

To assess the value of added transmission projects into a transmission capacity constrained scenario (the Reference scenario from above), we first add four new representative lines reinforcing the connections from the high wind states to the rest of the West. These four transmission lines, shown in Figure 8, total $10.5 \mathrm{GW}$ of new transmission capacity. All four lines represent proposed projects that have been or are being considered as effective means of transferring renewable energy out of relatively low load areas (WECC 2013). The projects, shown in Table 4, include the Mountain States Transmission Intertie (MSTI), Zephyr Power Transmission Project, TransWest Express Transmission Project, and SunZia Southwest Transmission Project.

We use these four proposed projects to estimate the value of transmission in reducing wind curtailment in the context of the Reference scenario. We do not intend to suggest that these projects are likely to succeed based on this analysis, nor is this a comprehensive benefit-to-cost analysis for any of these projects. In particular, we do not incorporate the capital costs listed in Table 4 of the new transmission (or new wind generation) in any of this analysis. Furthermore, we do not attempt to capture all potential benefit streams (such as the capacity value or voltage support provided by new transmission lines). A true cost-benefit analysis would consider each stream in detail. ${ }^{14}$ Our analysis considers only the avoided generation costs from a more efficient commitment and dispatch of the generator fleet enabled by additional transmission, which includes avoided curtailment.

\footnotetext{
${ }^{14}$ For an example of a detailed cost-benefit analysis of the TransWest Express transmission project considered here, see Corbus et al. (2014).
} 
Table 4. Proposed Transmission Projects Modeled in the Transmission 1 Scenario $^{a}$

\begin{tabular}{|c|c|c|c|}
\hline Transmission Line & $\begin{array}{c}\text { Estimated } \\
\text { Cost }(\$ B)\end{array}$ & Miles & MW-miles \\
\hline Zephyr (WY-NV) ${ }^{\mathrm{b}}$ & 3.5 & 950 & $2,900,000$ \\
\hline SunZia $(N M-A Z)^{c}$ & 2.6 & 515 & $1,500,000$ \\
\hline MSTI (MT - ID)d & 1.0 & 460 & 690,000 \\
\hline TransWest Express (WY - NV)e & 3 & 730 & $2,200,000$ \\
\hline Total & 10.1 & 2660 & $7,300,000$ \\
\hline
\end{tabular}

a We do not include these capital costs as part of a cost-benefit analysis of the buildout. They are shown only for comparative purposes.

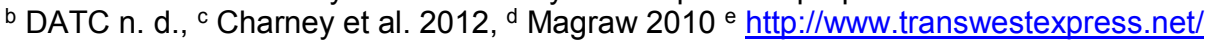

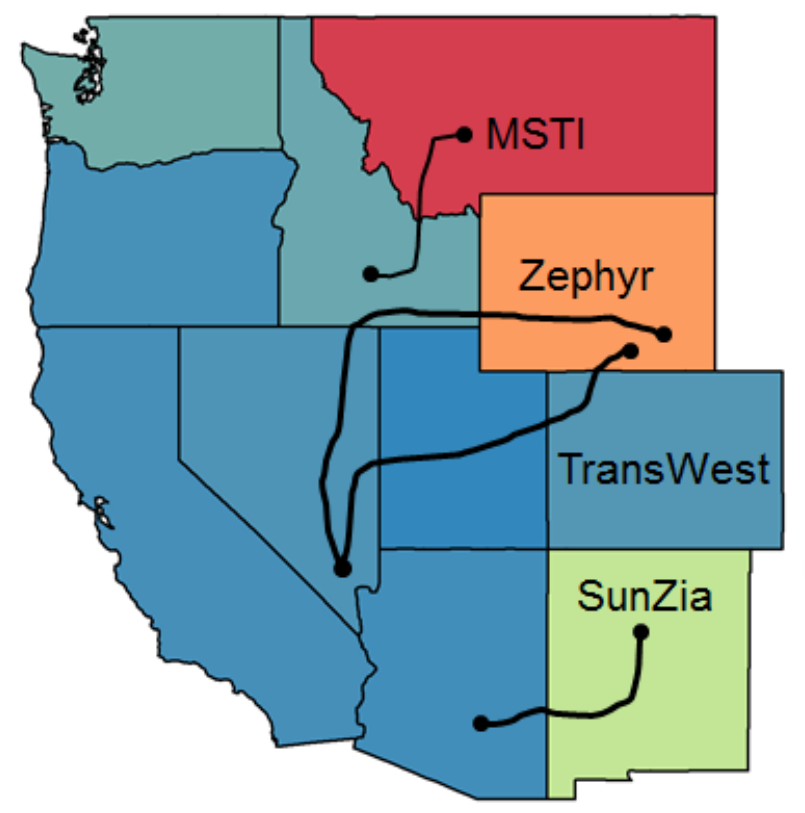

\begin{tabular}{|c|c|c|}
\hline Name & $\begin{array}{c}\text { Rating } \\
\text { (MW) }\end{array}$ & $\begin{array}{c}\text { Dist } \\
\text { (Mi) }\end{array}$ \\
\hline MSTI & 1500 & 460 \\
\hline Zephyr & 3000 & 950 \\
\hline $\begin{array}{c}\text { TransWest } \\
\text { Express }\end{array}$ & 3000 & 730 \\
\hline SunZia & 3000 & 515 \\
\hline
\end{tabular}

\section{Average Wind}

Penetration (\%)

200

100

Figure 8. Map of the Transmission 1 buildout, which adds four new lines to wind-heavy states

The addition of these four transmission lines has a definite impact on the Reference Wind Vision scenario. The annual curtailment is reduced by roughly half (15.5\% to $7.8 \%)$ through substantial curtailment reductions in the Mountain States, as shown in Figure 9. The change is significant despite the relatively small amount of transmission added (recall from Table 2 that there are approximately $55 \mathrm{GW}$ of wind capacity in Montana, New Mexico, and Wyoming in all scenarios). Figure 10 shows the heavy utilization of the new transmission lines. The plot sorts flow along each new line and indicates that flows on each line are at maximum capacity between about 3,700 and 6,300 hours per year. The MSTI line has a utilization factor ${ }^{15}$ of $87 \%$, meaning that on average the line uses $87 \%$ of its flow capacity in either direction, although Figure 10 indicates that the line is being used primarily to export energy west from Montana toward Idaho. The other lines have similarly high utilization factors: $70 \%$ for SunZia, $83 \%$ for the TransWest Express, and 82\% for Zephyr.

\footnotetext{
${ }^{15}$ Annual average of the absolute value of flow divided by capacity of the line
} 


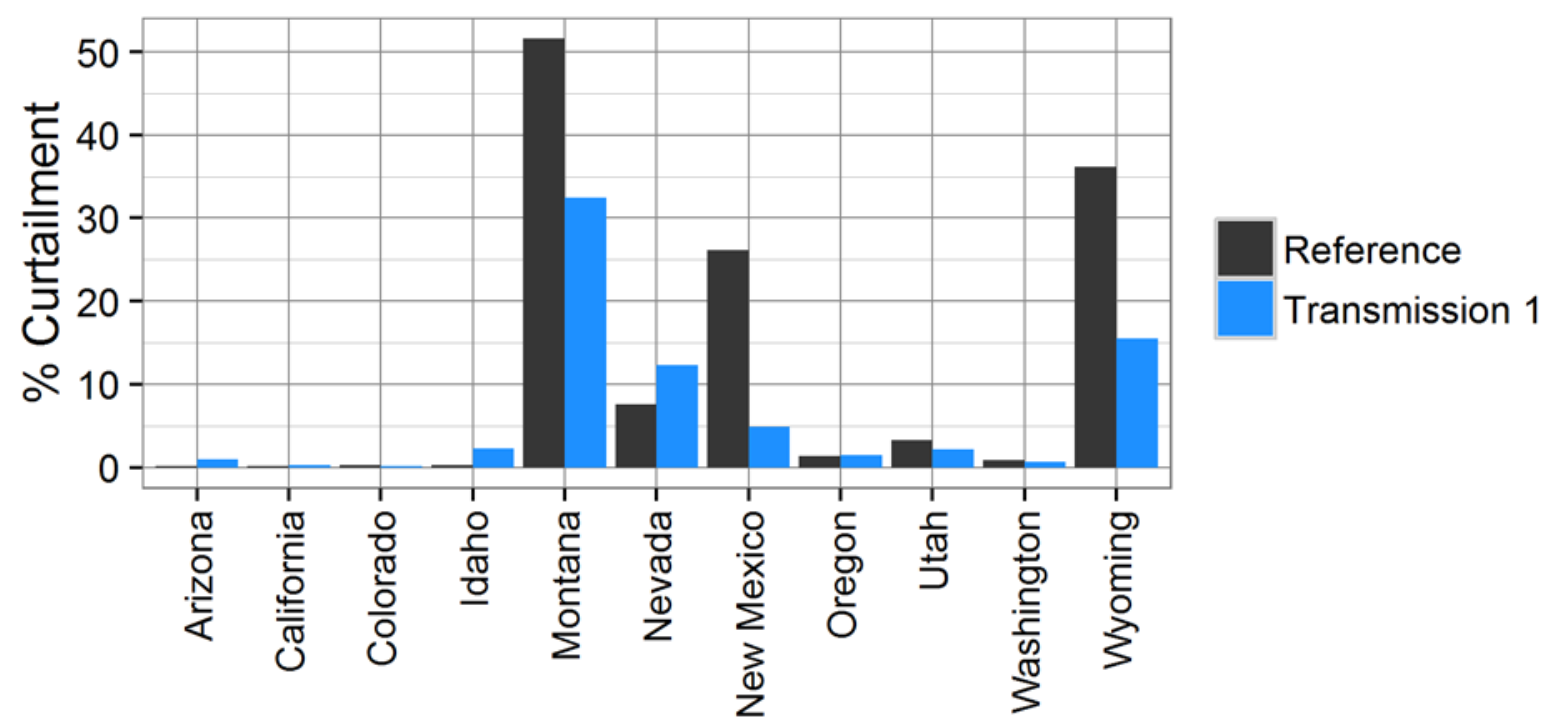

Figure 9. Annual curtailment in each state for the Transmission 1 buildout scenario compared to the Reference

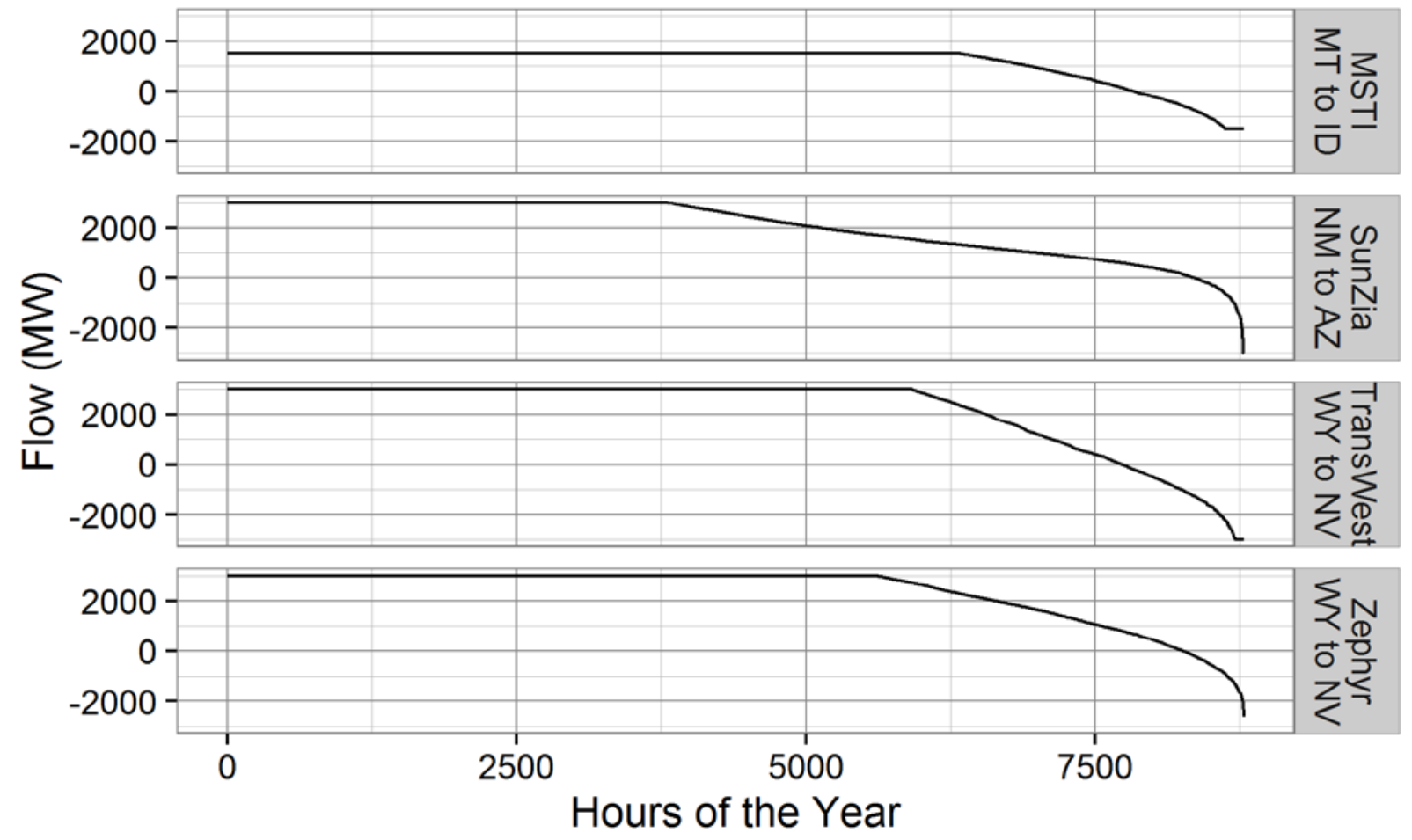

Figure 10. Flow duration cure for four added transmission lines 


\subsubsection{Second Transmission Buildout: Further increasing transmission capacity is useful but shows diminishing returns}

As discussed above, the first transmission buildout successfully reduced both curtailment and generation costs. To assess the value of further transmission capacity to reduce wind curtailment and production costs, we include the expanded transmission capacity from the Transmission 1 scenario, and we further expand transmission by about $8 \mathrm{GW}$, as shown in Figure 11. This second transmission buildout was selected by considering the WECC transmission plans, but more principally, it was informed by results of the first buildout. For instance, the extremely high utilization of the MSTI line in the first transmission buildout indicated that increasing capacity on that line could be beneficial. For this reason, we expanded the MSTI from 1,500 MW to 4,000 MW. This expansion of MSTI could simply cause congestion further west by potentially overwhelming the Southwest Intertie Project ${ }^{16}$ line from Idaho to Nevada, so we doubled the Southwest Intertie Project capacity in the Transmission 2 scenario as well. We also increased the capacity of Path 36 between Colorado and Wyoming because, as illustrated in Figure 9, Colorado curtailment is near zero and could be an effective sink for Wyoming wind. We also expand the SunZia line from 3,000 MW to 4,500 MW as the proposed project provides a range of capacity options. The results of this scenario indicate that this buildout does reduce curtailment by an additional $1.6 \%$, from $7.8 \%$ to $6.2 \%$. However, the marginal reduction in curtailment is small compared to that seen in the Transmission 1 scenario. It is important to remember that the Reference case is the most transmission-constrained system. Therefore, adding the first $10 \mathrm{GW}$ of transmission capacity into a more congested system will have a greater impact on curtailment reduction than the next $8 \mathrm{GW}$, as shown here.
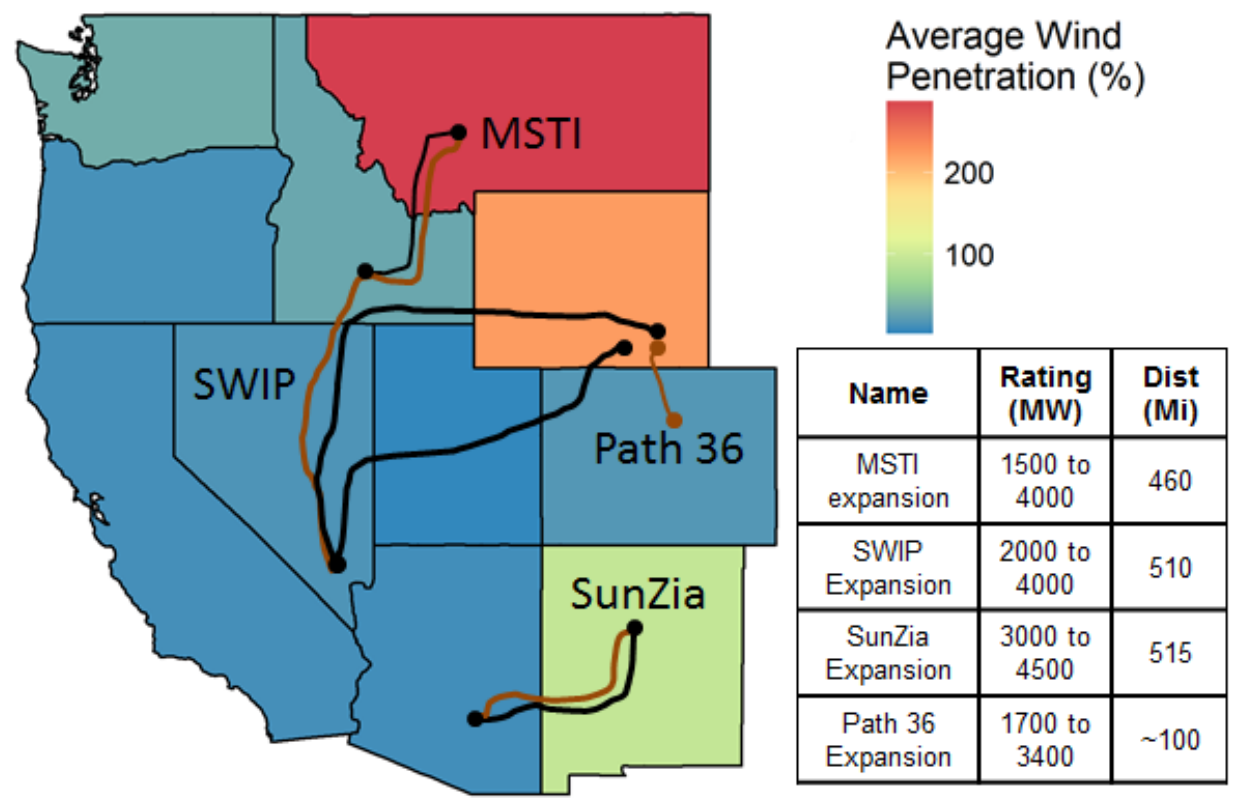

Figure 11. Map of the second transmission buildout, Transmission 2, which includes all four lines from the first buildout, and four more expansions

\footnotetext{
${ }^{16}$ Neither the Southwest Intertie Project, modeled at 2,000 MW in the Reference scenario, nor the Transmission 1 scenario exist yet. However, the line is included in this database as the result of the 2030 California Low Carbon Grid Study (Brinkman et al. 2016), in which the study team determined that the line was likely to exist by the year 2030 in scenarios with high renewable penetration in California (which is now required due to State Bill 350).
} 


\subsubsection{Third Transmission Buildout: A long transmission line directing Rocky Mountain wind toward the West Coast can help reduce wind curtailment}

Even after increasing transmission capacity out of the Mountain States to neighboring regions, we still see much higher levels of curtailment in the high-wind states compared to some other states, such as California. This indicates that certain states still may be able to accommodate more wind generation, but that wind energy cannot effectively reach those states. For the third transmission buildout, we incorporate a fictitious 3,000 MW line transporting energy from Montana and Wyoming to southern California. This line was designed to connect regions with low price (and high curtailment) to regions with higher prices (and lower curtailment rates). The results of this scenario further reduce curtailment by $1.8 \%$, from $6.2 \%$ to $4.4 \%$, annually. Figure 13 summarizes the curtailment in each of the three transmission buildouts, compared to the Reference and the Copper Sheet scenarios.

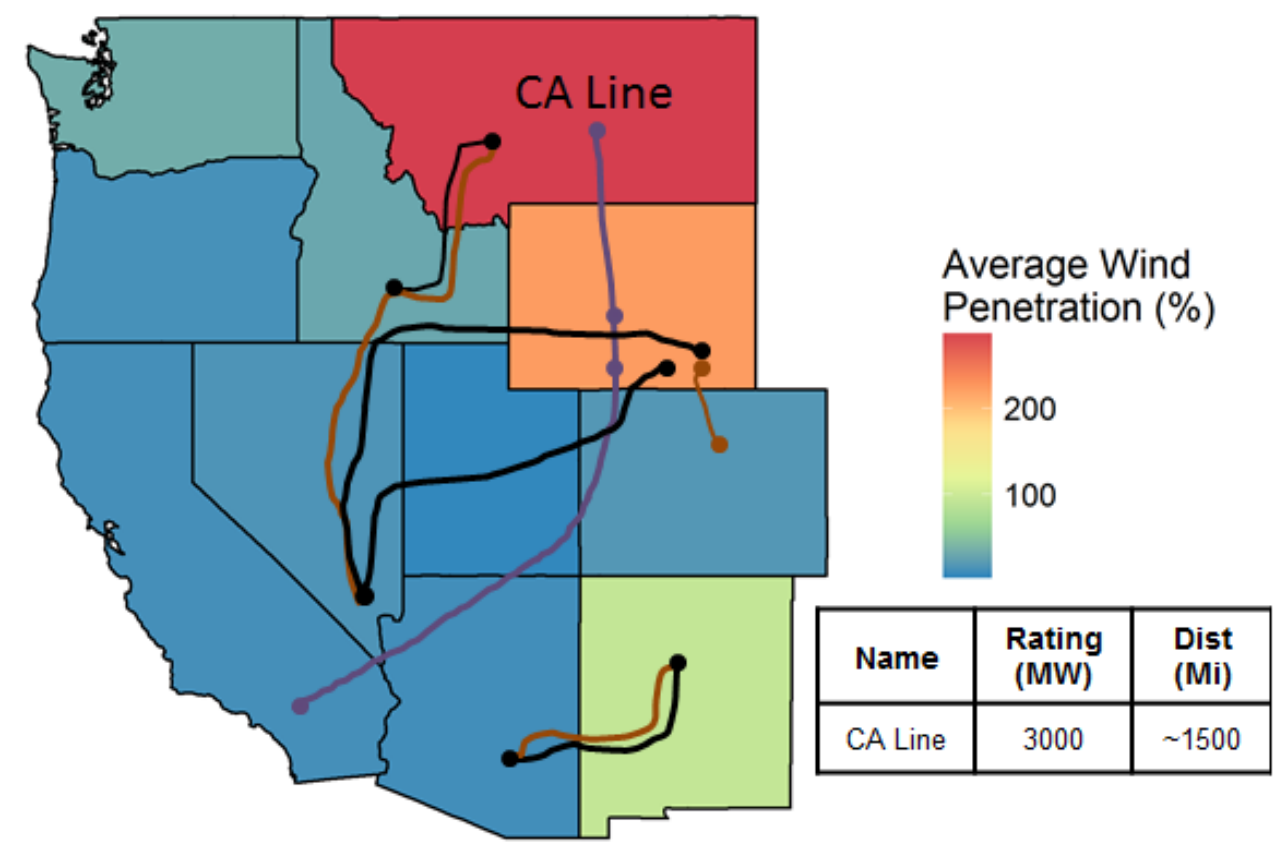

Figure 12. Map of the third transmission buildout, which includes a direct tie from the Mountain States to Southern California

Figure 14 illustrates the effect of the transmission buildout scenarios on imports and exports in each state. The new lines enable Montana, New Mexico, and Wyoming to export substantially more energy, which is depicted by an increase in their exports. Each other state in the West sees an increase in imports with the new transmission buildouts, meaning that wind energy from the Mountain States is displacing more generation in every other state. This indicates that the new transmission builds are enabling better use of wind energy in every state, not just the states in which each line begins and terminates. This is especially obvious in the difference between the Reference and Transmission 1 buildout scenarios. Although the second and third transmission builds show less dramatic changes, the Reference case is the most transmission-constrained system (as mentioned above). Therefore, adding the first $10 \mathrm{GW}$ of transmission capacity into a more congested system will have a greater impact than subsequently adding capacity. 


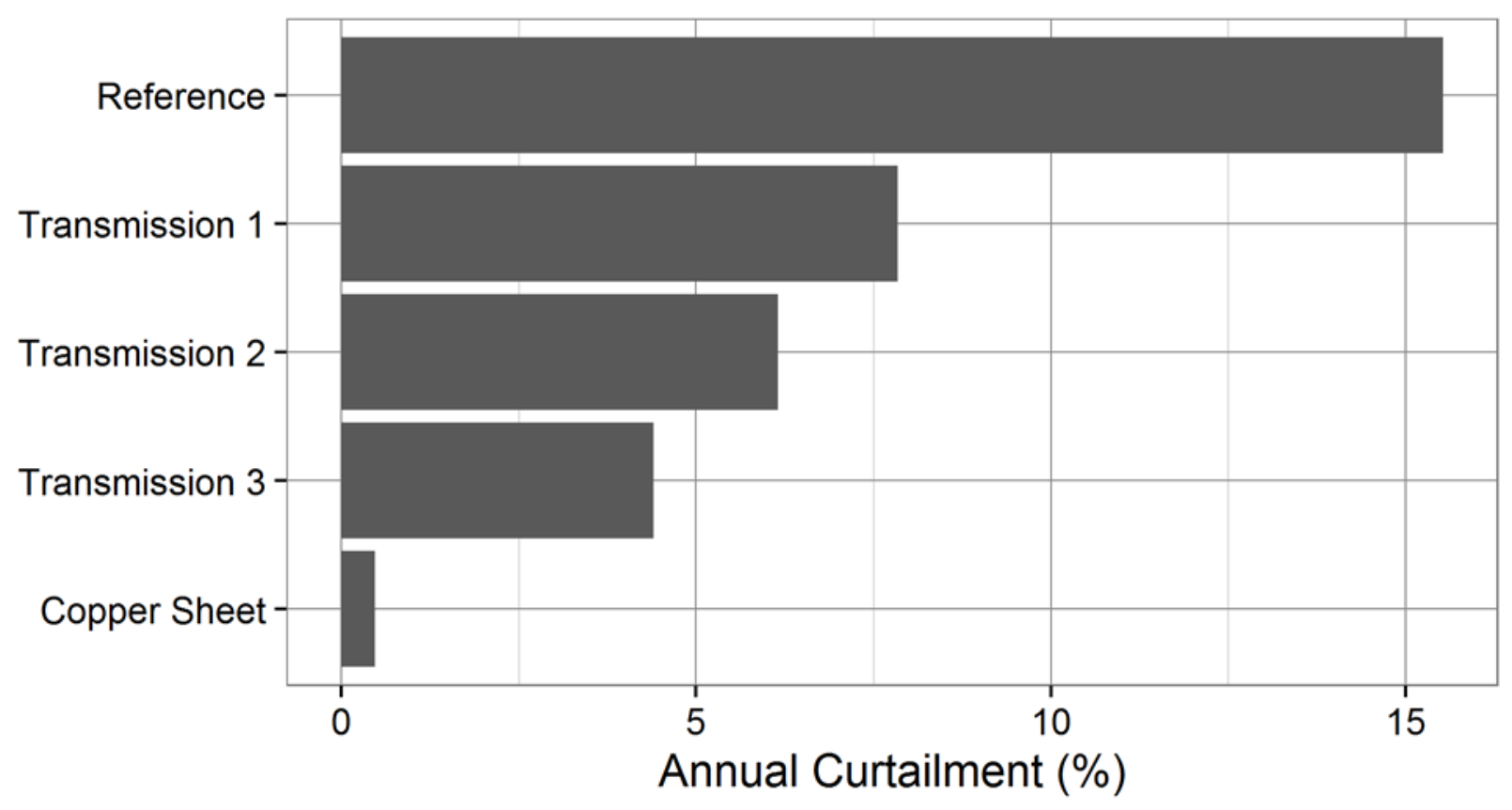

Figure 13. Total annual curtailment in five scenarios

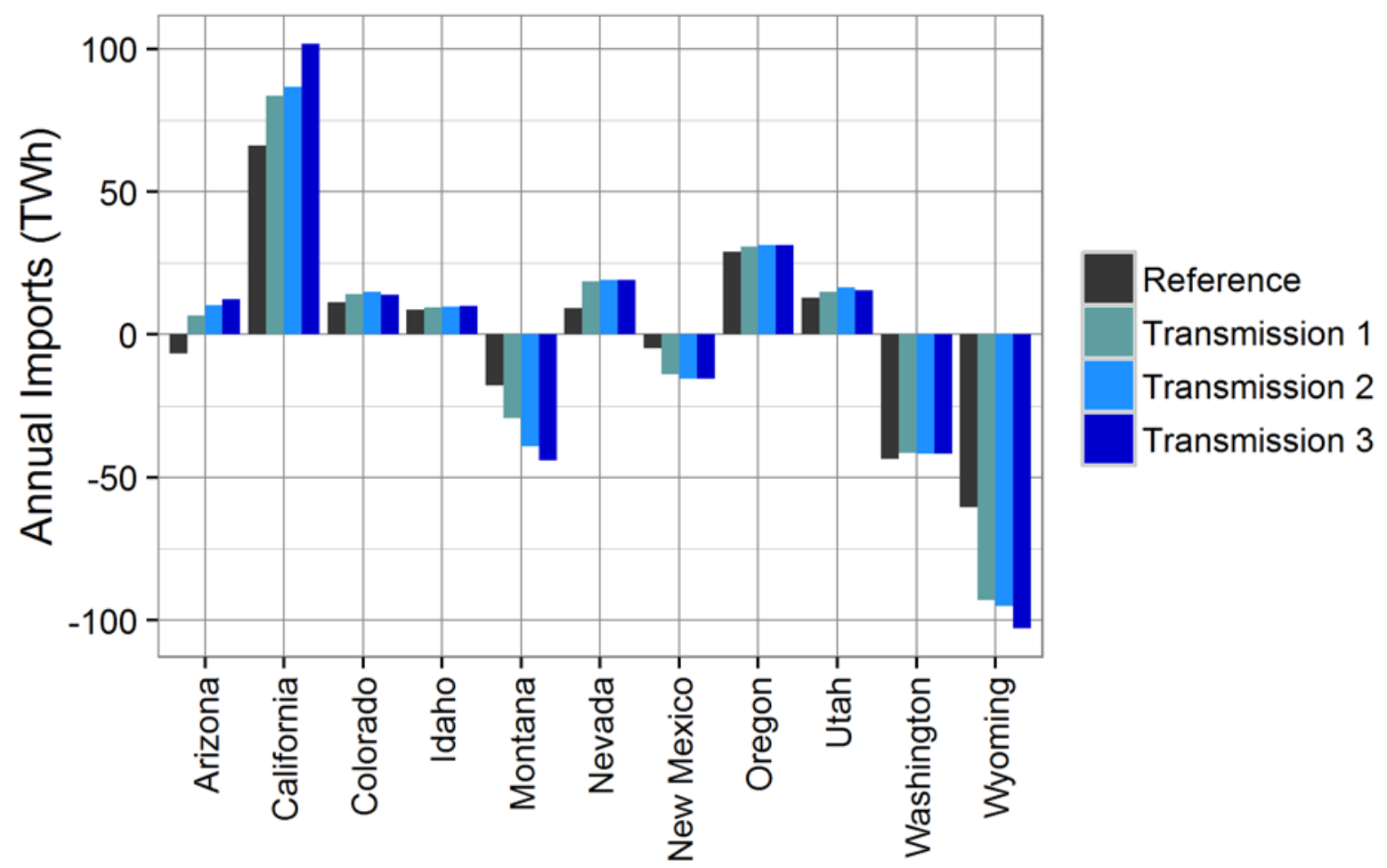

Figure 14. Annual imports for each state for the three transmission buildout scenarios compared to the Reference case 


\subsubsection{Cost and Emissions Results of the Transmission Buildout Scenarios: Transmission can help avoid generation costs and emissions, but with diminishing returns}

Additional transmission capacity can reduce total generation costs, primarily by transmitting lower cost energy to displace higher cost energy elsewhere. As mentioned, this operational analysis does not include the upfront capital costs required to build the modeled transmission buildouts or any of the generators. In addition, we do not include all sources of value for new transmission lines, which might include capacity value and voltage support. However, we do calculate the avoided generation costs as a result of each buildout. This includes an increased use of zero-marginal cost wind energy that otherwise would be curtailed and an increased use of less expensive generators. Table 5 shows the annual generation cost and carbon dioxide emissions for each of the transmission buildout scenarios.

Table 5. Summary of the Cost and Emissions of the Transmission Sensitivities

\begin{tabular}{lccccc}
\hline Scenario & $\begin{array}{c}\text { Total } \\
\text { Generation } \\
\text { Cost (\$B/yr) }\end{array}$ & $\begin{array}{c}\text { Cost Savings } \\
\text { compared to } \\
\text { Reference } \\
\text { (\$B/yr) }\end{array}$ & $\begin{array}{c}\text { Annual } \\
\mathbf{C O}_{2} \\
(\mathbf{M M T})\end{array}$ & $\begin{array}{c}\mathbf{C O}_{2} \text { Savings } \\
\text { compared to } \\
\text { Reference } \\
\text { (MMT) }\end{array}$ & $\begin{array}{c}\text { Annual } \\
\text { Curtailment } \\
\text { (\%) }\end{array}$ \\
\hline Reference & 19.6 & - & 308 & - & $15.5 \%$ \\
Transmission 1 & 17.3 & 2.3 & 289 & 19 & $7.8 \%$ \\
Transmission 2 & 16.9 & 2.6 & 281 & 27 & $6.2 \%$ \\
Transmission 3 & 16.2 & 3.4 & 280 & 28 & $4.4 \%$ \\
Copper Sheet & 14.3 & 5.3 & 293 & 15 & $0.5 \%$ \\
\hline
\end{tabular}

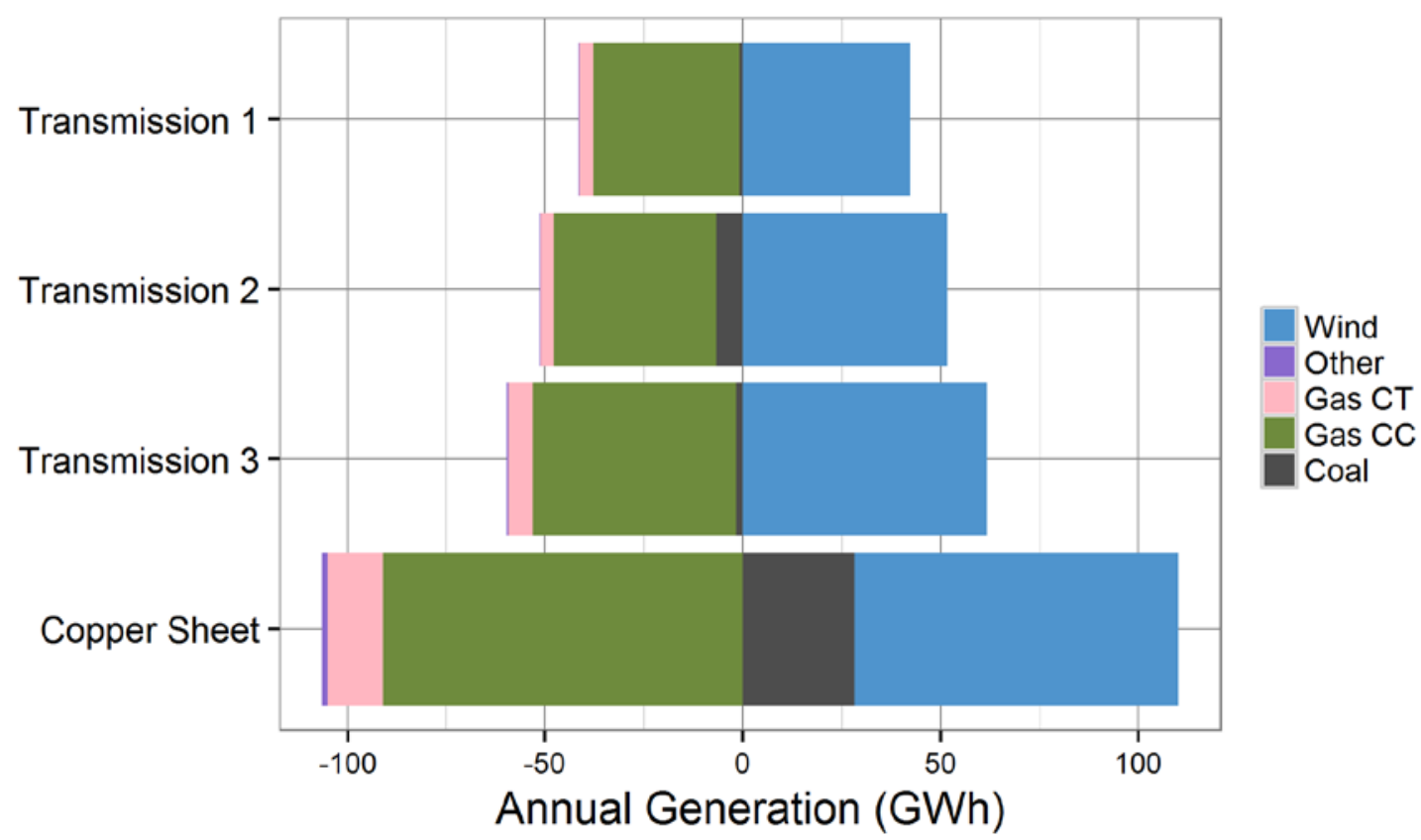

Figure 15. Change in generation in four transmission buildout scenarios compared with the Reference scenario

Positive values indicate increased generation, while negative numbers indicate displaced generation. 
Figure 15 (above) shows the difference in generation by source for each of the scenarios in Table 5 compared to the Reference and helps explain the differences between the scenarios. For each transmission buildout, we see that substantially higher generation from wind is instead curtailed in the Reference scenario (indicated by the positive scale on the plot). We also see a substantial reduction of natural gas generation, primarily from Gas CCs (indicated by the negative scale on the plot). ${ }^{17}$ The Copper Sheet scenario also enables a substantial increase in coal generation along with the increase in wind generation, displacing more expensive gas generation. This increase in coal generation explains why the carbon savings are actually lower in the Copper Sheet scenario than they are in the rest of the three transmission buildouts.

This figure underscores another important point: the generation cost savings from Table 5 are very dependent on the cost of the displaced generation source (natural gas). Natural gas prices are historically volatile and challenging to predict. As mentioned in Section 2, we assume a delivered natural gas price of $\$ 6.7 / \mathrm{MMBtu}$ on average, although the price varies by month and region. In an attempt to capture some uncertainty in this forecast, we also assess the impact of gas prices $25 \%$ below $(\$ 5.0 / \mathrm{MMBtu})$ and above $(\$ 8.4 / \mathrm{MMBtu})$ that average. To be clear, we did not re-run the dispatch simulations with varying gas prices but only incorporated the effect of different prices on generation costs in post-processing. Slightly different gas prices are unlikely to substantially affect the dispatch of the system, as natural gas plants more expensive than coal generation in all price sensitivities, given that the modeled coal cost is about \$2/MMBtu and no carbon costs were modeled. Table 6 and Table 7 show the results of this sensitivity. Unsurprisingly, the total generation cost increases with increasing natural gas prices, as does the value of the transmission buildout scenarios. Even with lower natural gas prices, the transmission buildout scenarios show substantial value, between $\$ 1.8$ billion dollars and $\$ 2.6$ billion dollars annually.

The annual operational savings of \$1.8-2.8 billion for the Transmission 1 scenario can be compared with reported transmission capital cost ( $\$ 10.1$ billion) from Table 4.Using a simple calculation (ratio of reported transmission capital cost to annual operation savings) we find a simple payback period of about 4.4 years in the central gas price scenario and less than six years in all natural gas price sensitivities. Although this simple calculation suggests a strong economic case for transmission, there are a number of caveats to consider. First, estimated transmission costs used for the simple payback calculation are based on reported numbers for proposed projects, which may differ from actual costs. ${ }^{18}$ Second, this payback calculation does not take into account capital cost for new capacity, including new wind capacity. Third, our analysis does not, on the other hand, include other potential benefits of new transmission such as reduced firm capacity needs. Finally, although the system-wide economic case for transmission expansion might be strong, numerous other issues, such as cost and savings allocations, related to new transmission need to be considered.

\footnotetext{
17 The graph in Figure 15 could also hide another source of generation cost savings: generation switching within generator type. For instance, a new transmission buildout could enable a slightly less expensive Gas CC generator to run while displacing a more expensive Gas CC generator elsewhere on the network. On the plot, the two would be cancelled out, while the generation savings would still be realized.

${ }^{18}$ Other transmission cost estimates, including transmission cost assumptions ranging from about $\$ 900 / \mathrm{MW}$-mile to over $\$ 3500 / \mathrm{MW}$-mile used in the Wind Vision analysis, can be used to develop different transmission capital cost estimates.
} 
Table 6. The Sensitivity of Annual Generation Cost on Natural Gas Price

\begin{tabular}{llll}
\hline Scenario & $\begin{array}{l}\text { Total } \\
\text { Generation } \\
\text { Cost }(\$ B / y r)\end{array}$ & $\begin{array}{l}\text { High Gas } \\
\text { Generation } \\
\text { Cost (\$B/yr) }\end{array}$ & $\begin{array}{l}\text { Low Gas } \\
\text { Generation } \\
\text { Cost (\$B/yr) }\end{array}$ \\
\hline Reference & 19.6 & 23.1 & 16.2 \\
Transmission 1 & 17.3 & 20.2 & 14.4 \\
Transmission 2 & 16.9 & 19.8 & 14.1 \\
Transmission 3 & 16.2 & 18.9 & 13.6 \\
Copper Sheet & 14.3 & 16.4 & 12.2 \\
\hline
\end{tabular}

a This column represents the original assumption of $\$ 6.7 / \mathrm{MMBtu}$ average delivered price.

Table 7. The Savings Associated with Transmission Buildouts under Natural Gas Price Sensitivities

\begin{tabular}{lccc}
\hline Scenario & $\begin{array}{l}\text { Savings from } \\
\text { Reference (\$B/yr) }\end{array}$ & $\begin{array}{l}\text { High Gas Savings } \\
\text { from Reference } \\
\mathbf{( \$ B / y r )}\end{array}$ & $\begin{array}{l}\text { Low Gas Savings from } \\
\text { Reference } \mathbf{( \$ B / y r )}\end{array}$ \\
\hline Reference & - & - & - \\
Transmission 1 & 2.3 & 2.8 & 1.8 \\
Transmission 2 & 2.6 & 3.2 & 2.1 \\
Transmission 3 & 3.4 & 4.2 & 2.6 \\
Copper Sheet & 5.3 & 6.7 & 3.9 \\
\hline
\end{tabular}

\subsubsection{Comparison with ReEDS-generated 2050 Wind Vision Study Scenario}

The transmission buildouts modeled are not optimized for the generator buildout. As discussed, the ReEDS model, which was used to develop the 2050 Wind Vision Study Scenario, simultaneously optimizes generation and transmission. In this study, the transmission buildout is determined first based on proposed projects and is then expanded manually to improve wind integration. For the 2050 Wind Vision Study Scenario, ReEDS deployed about 23 GW of new transmission capacity (or 3.5 million MW-miles) between 2024 and 2050 in the Western Interconnection. This study adds $10.5 \mathrm{GW}$ (7.3 million MW-miles) in the Transmission 1 buildout, $18.5 \mathrm{GW}$ in the Transmission 2 buildout, and $21.5 \mathrm{GW}$ in the Transmission 3 buildout (or 14.9 million MW-miles). ${ }^{19}$ Therefore, the total capacity of transmission added (in the Transmission 3 scenario) is similar to the total new transmission between 2024 and 2050 in the Wind Vision Study Scenario. In fact, the Transmission 3 scenario has similar levels of curtailment (4\%) to the Wind Vision Study Scenario (3\%). Even though these two scenarios differ in composition slightly, this underscores the similarity between these two high wind futures.

\footnotetext{
${ }^{19}$ The ReEDS model attempts to minimize system costs, including transmission costs in units of \$/MW-mi, whereas our buildout did not attempt to shorten transmission distances. In addition, ReEDS uses geodesic distances to measure transmission builds between model regions. These two differences help explain the disparity in transmission distances between the 2050 Wind Vision Study Scenario and this analysis.
} 
These results partially validate the ReEDS modeling for the Wind Vision study despite ReEDS' reduced-form dispatch modeling and more simplistic transmission representations. Specifically, our finding of operational feasibility across all the high wind scenarios demonstrates the plausibility of the ReEDS-generated Wind Vision Study Scenario. Moreover, ReEDS-estimated curtailments are aligned with our estimates when similar transmission capacity expansion occurs, although the transmission line distances differ in the Wind Vision Study Scenario compared to the ones considered for this study.

\subsection{Enforcing suboptimal transmission flows shows the importance of real-time balancing on reducing costs and curtailment}

Up until this point, we have only considered optimal power flow, respecting nodal transmission constraints. In the real world, however, non-physical constraints may prevent power flow from being fully optimized. For instance, much of the Western Interconnection uses contracts to schedule transmission and generation rather than the cost-minimization we use here. These bilateral contracts (which are generally proprietary and therefore not modeled here) may lead to out-of-merit use of transmission and generator capacity.

Brinkman (2015), using a proxy for suboptimal transmission scheduling, showed that constraining existing transmission can have an adverse effect on generation costs and renewable energy integration. ${ }^{20}$ Our sensitivity in the present analysis likewise incorporates the impact of suboptimal transmission scheduling on wind curtailment and generation costs. Because, as mentioned, we do not incorporate bilateral agreements and inefficient transmission scheduling into the modeling, we instead use a proxy for inefficient transmission schedules. First, we use the optimized flows from the day-ahead simulation in the Transmission 1 scenario discussed above. Then, we require the day-ahead flows to be enforced in the real-time simulation for ten of the largest modeled transmission paths. Enforcing the day-ahead optimal flows will already create a small element of inefficiency, as the model will not be able to adjust flows based on the actual wind and solar generation in the real time. Next, we add varying degrees of noise to the ideal transmission flow along these paths. The noise is introduced by adding normally distributed error scaled relative to the magnitude of average flow along the path. Here, we add error that is scaled by $10 \%, 25 \%$, or $50 \%$ of average flow magnitude. Figure 16 shows a sample of the optimal flow, and flows with error imposed (labeled as low, medium, and high error). We enforce these flows in the day-ahead, intra-day, and real-time operations, because underlying inefficient transmission scheduling would affect all scheduling horizons. For instance, the commitment of coal generators in the day-ahead could be affected by transmission schedules.

\footnotetext{
${ }^{20}$ Brinkman (2015) used hurdle rates to impact transmission schedules. Specifically, the analysis implemented a \$40/MWh hurdle rate which meant that energy would have to be more than $\$ 40 / \mathrm{MWh}$ less in Region A than in Region B for Region B to import power from Region A. For instance, Region B might turn on a Gas CC generator rather than accept free energy from Region B.
} 


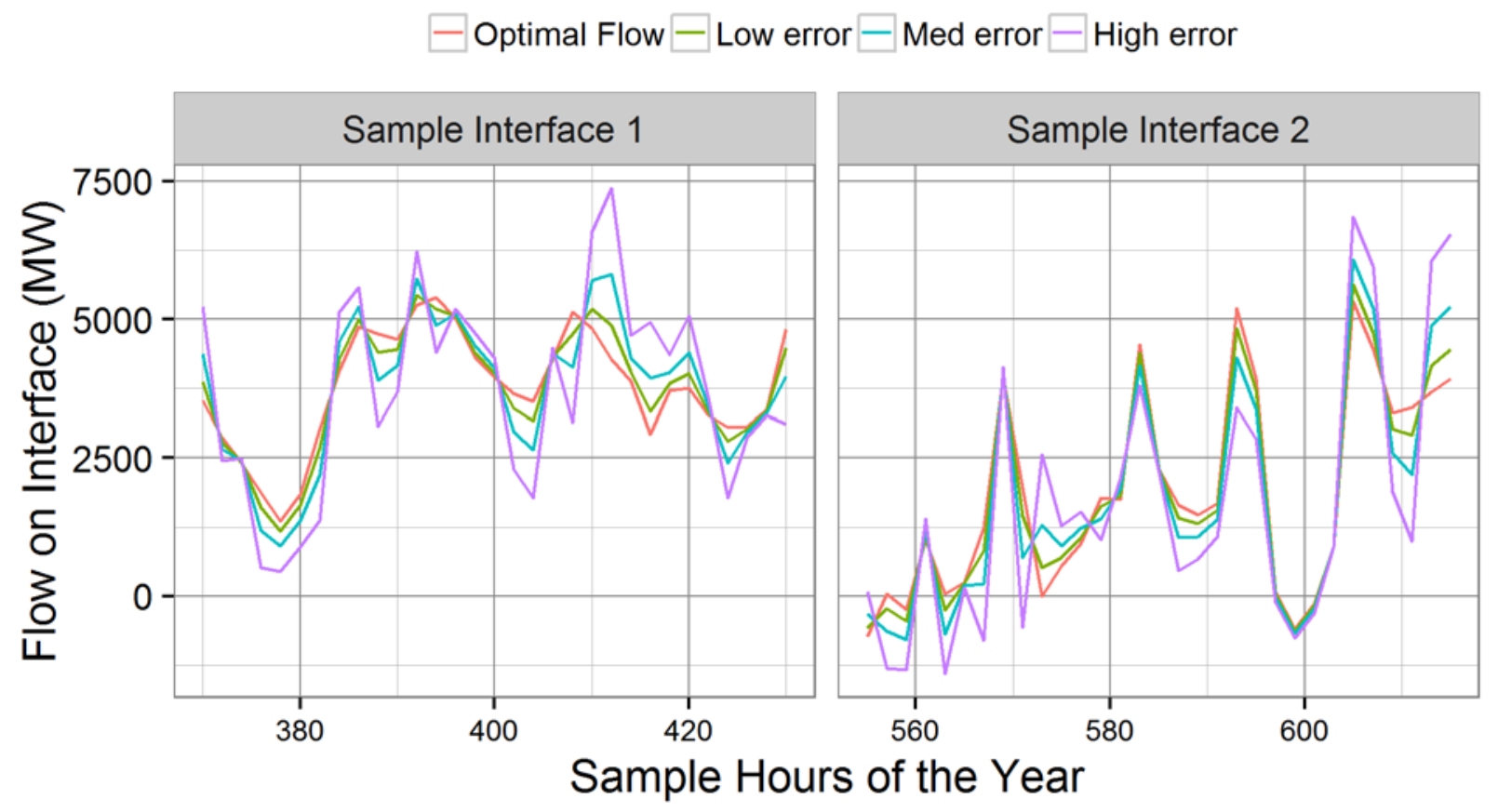

Figure 16. Sample representation of non-optimal flow enforced in this sensitivity

First we find that locking the day-ahead flows through to the real-time for the ten selected large transmission paths results in a substantial (1.4 percentage point) increase in curtailment and increases annual generation costs by nearly $\$ 1$ billion. This indicates that optimizing flows in the real-time in response to actual generating conditions for wind and solar provides significant benefit. Conversely, if the model cannot capture the inflexibility of certain transmission contracts, these results suggest that modeled curtailment may be underestimated due to realworld constraints that are difficult to model.

Introducing a low amount of error to the day-ahead flows results in a small increase in annual curtailment and annual costs. Interestingly, the low error case shows slightly lower annual emissions than the Transmission 1 scenario or the Transmission 1 scenario with locked DA flows while raising annual production costs. Figure 17, which shows the change in generation for each of the sub-optimal transmission scenarios, helps explain this result. The figure indicates that the low error case displaces a higher proportion of coal generation with lower-emitting gas generation than does the case with only locked DA schedules. The medium and high error cases further increase curtailment, costs, and emissions. 


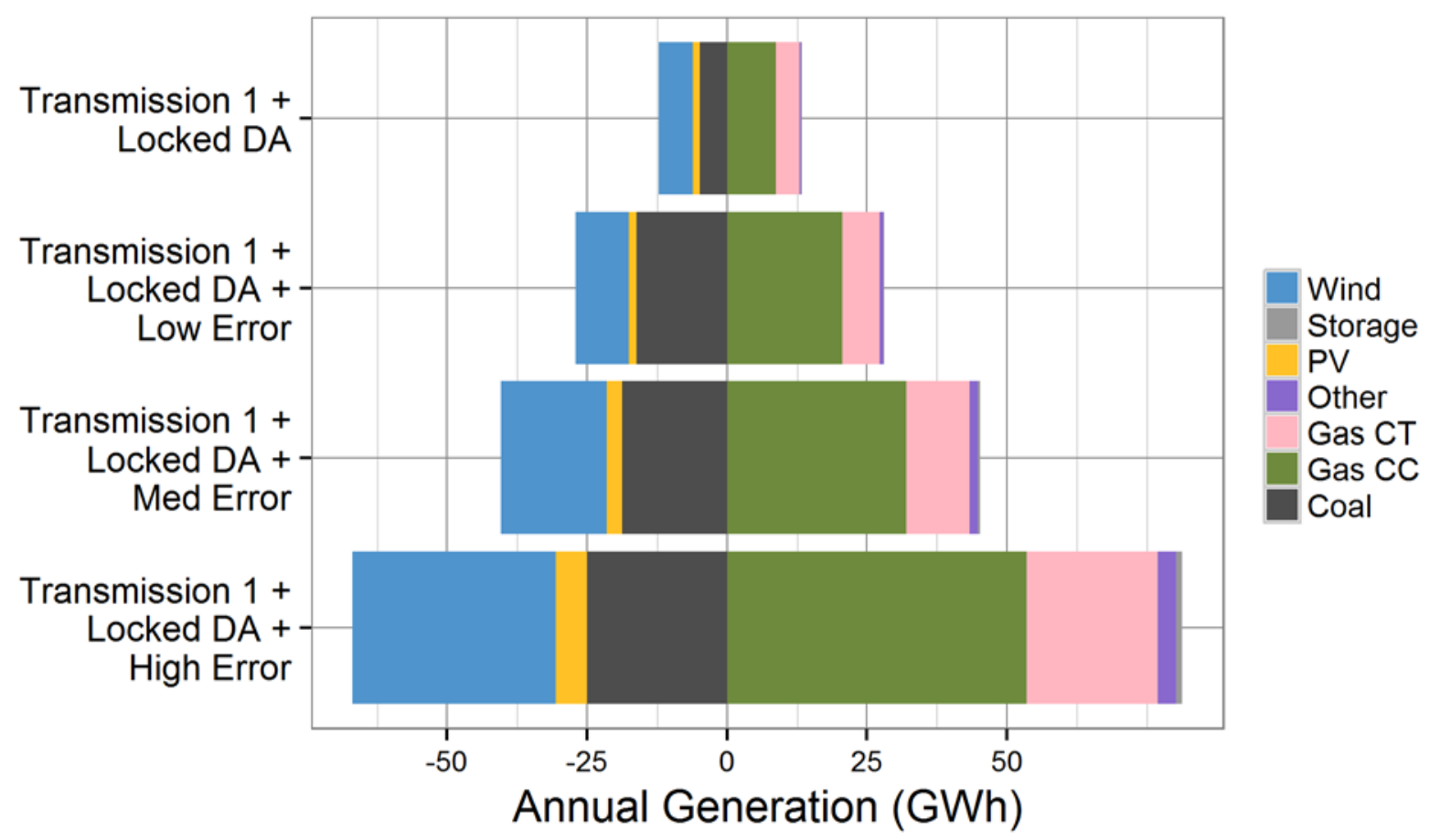

Figure 17. Change in generation in sub-optimal transmission scenarios compared with the Transmission 1 scenario

Positive values indicate increased generation, while negative numbers indicate displaced generation.

Although this method of introducing error into transmission flows is simply a proxy for other factors that could influence line flows, it still shows the potential substantial effect of enforcing suboptimal transmission flows. Firstly, enforcing transmission schedules from the day-ahead in the real-time has a significant impact in increasing costs and curtailment. This underscores the importance of real-time balancing, especially in cases with high shares of wind and solar, which are somewhat uncertain until the real-time. Low levels of error can be absorbed with a relatively small impact, but in the high error case, annual curtailment nearly doubles, and generation costs increase by $\$ 5$ billion annually (see Table 8 ). Overall, this sensitivity provides a method to begin to quantify the benefits of centrally operated transmission and generation, which can be a key factor in limiting renewable integration problems. Assuming an optimal West-wide dispatch (as is used in this study and in much previous research) may overlook some non-economic barriers to renewable energy integration. Further research is needed to understand how transmission infrastructure is utilized and the degree of sub-optimality existent in real transmission networks. 
Table 8. Total Curtailment, Generation Cost, and Carbon Emissions in Sub-Optimal Transmission Scenarios

\begin{tabular}{lccc}
\hline Scenario & $\begin{array}{l}\text { Total } \\
\text { Generation } \\
\text { Cost (\$B/yr) }\end{array}$ & $\begin{array}{l}\text { Annual } \\
\text { Curtailment } \\
(\%)\end{array}$ & $\begin{array}{l}\text { Annual Carbon } \\
\text { Emissions } \\
\text { (MMT) }\end{array}$ \\
\hline Transmission 1 & 17.3 & $7.8 \%$ & 289 \\
Transmission 1 - Locked Flows from DA & 18.2 & $9.2 \%$ & 291 \\
Transmission 1 - Locked Flows + Low Error & 18.8 & $9.8 \%$ & 287 \\
Transmission 1 - Locked Flows + Medium Error & 19.9 & $11.8 \%$ & 293 \\
Transmission 1 - Locked Flows + High Error & 22.3 & $15.7 \%$ & 305 \\
\hline
\end{tabular}




\section{Conclusions}

In this study, we conduct a detailed operational analysis of a scenario based on DOE's Wind Vision Study Scenario for the year 2050. Specifically, we compose a high wind scenario in the western United States that has 37\% wind energy available (and 12\% PV energy) with a geographical distribution similar to that of the Wind Vision Study Scenario. While we find that this scenario is technically feasible, we observe high levels $(15.5 \%)$ of renewable energy curtailment without major infrastructure changes to the power grid. Specifically, we find that the existing transmission capacity is insufficient to transmit high amounts of wind energy in the Mountain States to the more populated coastal regions. In fact, a scenario with no transmission constraints reduces curtailment to $0.5 \%$. In contrast, we find that retiring coal baseload generation only has a marginal impact on curtailment, reducing curtailment from only $15.5 \%$ to $14.9 \%$.

To assess the value of transmission in mitigating wind curtailment and generation costs, we also model a suite of three transmission expansion scenarios. We find that wind curtailment can be approximately reduced by half, to roughly $7.8 \%$, under a scenario where new transmission is based only on four proposed projects throughout the West. This avoided wind curtailment can lower annual production costs and reduce carbon dioxide emissions substantially. Greater transmission expansion was found to yield further benefits (in both curtailment and cost reduction), although the marginal benefits of these new lines were found to decline beyond the initial buildout. Overall, these results suggest that effective power system operation can be realized with $37 \%$ wind penetration (and 12\% PV penetration), but that transmission expansion is likely to play a vital role in allowing for efficient usage of renewable resources. 


\section{References}

AWEA (American Wind Energy Association). 2016. Annual Market Report.

Bird, Lori, Jaquelin Cochran, and Xi. Wang. 2014. Wind and Solar Energy Curtailment: Experience and Practices in the United States. Golden, CO: National Renewable Energy Laboratory. NREL/TP-6A20-60983. http://www.nrel.gov/docs/fy14osti/60983.pdf.

Bloom, Aaron, Aaron Townsend, David Palchak, Joshua Novacheck, Jack King, Clayton Barrows, Eduardo Ibanez, Matthew O'Connell, Gary Jordan, Billy Roberts, Caroline Draxl, and Kenny Gruchalla. 2016. Eastern Renewable Generation Integration Study. Golden, CO: National Renewable Energy Laboratory. NREL/TP-6A20-64472.

http://www.nrel.gov/docs/fy16osti/64472.pdf.

Brinkman, Gregory. 2015. Renewable Electricity Futures: Operational Analysis of the Western Interconnection at Very High Renewable Penetrations. Golden, CO: National Renewable Energy Laboratory. NREL/TP-6A20-64467. http://www.nrel.gov/docs/fy15osti/64467.pdf.

Brinkman, Gregory, Jennie Jorgenson, Ali Ehlen, and James H. Caldwell. 2016. Low Carbon Grid Study: Analysis of a 50\% Emission Reduction in California. Golden, CO: National Renewable Energy Laboratory. NREL/TP-6A20-64884. http://www.nrel.gov/docs/fy16osti/64884.pdf.

Charney, Alberta H., Valorie Rice, Marshall J. Vest, Anthony V. Popp, James Peach, and Leo Delgado. 2012. SunZia Southwest Transmission Project Economic Impact Assessment. Revised January 2012. http://www.sunzia.net/documents_pdfs/sunzia_eia_revised_final_jan_2012.pdf

Cole, Wesley, Trieu Mai, Jeffery Logan, Daniel Steinberg, James McCall, James Richards, Benjamin Sigrin, and Gian Porro. 2016. Standard Scenarios Report: A U.S. Electricity Sector Outlook. Golden, CO: National Renewable Energy Laboratory. NREL/TP-6A20-66939. http://www.nrel.gov/docs/fy17osti/66939.pdf.

Corbus, D., D. Hurlbut, P. Schwabe, E. Ibanez, M. Milligan, G. Brinkman, A. Paduru, V. Diakov, and M. Hand. 2014. California-Wyoming Grid Integration Study Phase 1: Economic Analysis. Golden, CO: National Renewable Energy Laboratory. NREL/TP-6A20-61192. http://www.nrel.gov/docs/fy14osti/61192.pdf.

CPUC (California Public Utilities Commission). 2016. RPS Calculator User Guide, Version 6.2.

Denholm, Paul, Matthew O'Connell, Gregory Brinkman, and Jennie Jorgenson. 2015. Overgeneration from Solar Energy in California: A Field Guide to the Duck Chart. Golden, CO: National Renewable Energy Laboratory. NREL/TP-6A20-65023. http://www.nrel.gov/docs/fy16osti/65023.pdf

Denholm, P., J. Novacheck, J. Jorgenson, and M. O'Connell. 2016. Impact of Flexibility Options on Grid Economic Carrying Capacity of Solar and Wind: Three Case Studies. Golden, CO: National Renewable Energy Laboratory. 
Denholm, Paul, and Robert Margolis. 2016. Energy Storage Requirements for Achieving 50\% Solar Photovoltaic Energy Penetration in California. Golden, CO: National Renewable Energy Laboratory. NREL/TP-6A20-66595. http://www.nrel.gov/docs/fy16osti/66595.pdf

DOE (U.S. Department of Energy). 2015. Wind Vision: A New Era for Wind Power in the United States. Washington, D.C.: U.S. Department of Energy. DOE/GO-102015-4557. http://www.energy.gov/sites/prod/files/WindVision_Report_final.pdf.

DATC (Duke American Transmission Co.). n. d. Zephyr Power Transmission Project. http://www.datcllc.com/wp-content/uploads/2012/02/ZephyrProject-Web.pdf.

E3 (Energy and Environmental Economics). 2014. Investigating a Higher Renewables Portfolio Standard in California. San Francisco, CA: Energy and Environmental Economics. https://ethree.com/documents/E3_Final_RPS_Report_2014_01_06_with_appendices.pdf

EIA (Energy Information Administration. 2014. Annual Energy Outlook 2014 with Projections to 2040. DOE/EIA-0383(2014). http://www.eia.gov/forecasts/aeo/pdf/0383(2014).pdf

- 2016. Short-Term Energy Outlook: Renewables and Carbon Dioxide Emissions. Accessed September 14, 2016. https://www.eia.gov/forecasts/steo/report/renew_co2.cfm

Eurek, Kelly, Wesley Cole, David Bielen, Nate Blair, Stuart Cohen, Bethany Frew, Jonathan Ho, Venkat Krishnan, Trieu Mai, Benjamin Sigrin, and Daniel Steinberg. 2016. Regional Energy Deployment System (ReEDS) Model Documentation: Version 2016. NREL/TP-6A20-67067. Golden, CO: National Renewable Energy Laboratory. http://www.nrel.gov/docs/fy17osti/67067.pdf.

GE Energy Consulting. 2014a. PJM Renewable Integration Study: Executive Summary Report, Revision 03. Prepared for PJM Interconnection, LLC. https://www.pjm.com/ /media/ committees-groups/committees/mic/20140303/20140303-pris-executive-summary.ashx.

- 2014b. Minnesota Renewable Energy Integration and Transmission Study. Prepared for the Minnesota Utilities and Transmission Companies and the Minnesota Department of Commerce. http://mn.gov/commerce-stat/pdfs/mrits-report-2014.pdf.

Lew, D., G. Brinkman, E. Ibanez, A. Florita, M. Heaney, B.-M. Hodge, M. Hummon, G. Stark, J. King, S.A. Lefton, N. Kumar, D. Agan, G. Jordan, and S. Venkataraman. 2013. The Western Wind and Solar Integration Study Phase 2. Golden, CO: National Renewable Energy Laboratory. NREL/TP-5500-55588. http://www.nrel.gov/docs/fy13osti/55588.pdf.

MacDonald, Alexander E., Christopher T. M. Clack, Anneliese Alexander, Adam Dunbar, James Wilczak, and Yuanfu Zie. 2016. "Future Cost-Competitive Electricity Systems and their Impact on US $\mathrm{CO}_{2}$ Emissions." Nature Climate Change 6:526-531.

Magraw , Chuck. 2010. "More Woes for MSTI Transmission Line.” The Energy Activist 12(1, Summer 2010). http://www.nwenergy.org/uncategorized/more-woes-for-msri-transmission-line/. 
Nelson, James H., and Laura M. Wisland. 2015. Achieving 50 Percent Renewable Electricity in California: The Role of Non-Fossil Flexibility in a Cleaner Electricity Grid. Oakland, CA: Union of Concerned Scientists. http://www.ucsusa.org/sites/default/files/attach/2015/08/Achieving-50-Percent-RenewableElectricity-In-California.pdf.

PLEXOS Integrated Energy Model version 7.200 R03 x64 Edition [software]. 2016. www.energyexemplar.com.

Short, Walter, Patrick Sullivan, Trieu Mai, Matthew Mowers, Caroline Uriarte, Nate Blair, Donna Heimiller, and Andrew Martinez. 2011. Regional Energy Deployment System (ReEDS). Golden, CO: National Renewable Energy Laboratory. NREL/TP-6A20-46534. http://www.nrel.gov/docs/fy12osti/46534.pdf.

WECC (Western Electricity Coordinating Council). 2013. 2022 Resource Options, PC19-PC25. Available for download at http://www.wecc.biz.

- 2015. TEPPC Study Report-2024 PC1 Common Case and Release Notes for WECC 2024 Common Case Version 1.1. Available for download at http://www.wecc.biz.

Wiser, Ryan, and Mark Bolinger. 2016. 2015 Wind Technologies Market Report. Berkeley, CA: Lawrence Berkeley National Laboratory. DOE/GO-10216-4885. https://emp.lbl.gov/sites/all/files/2015-windtechreport.final .pdf. 